\title{
The effects of graded levels of calorie restriction: $V$. Impact of short term calorie and protein restriction on physical activity in the C57BL/6 mouse
}

\author{
Sharon E. Mitchell ${ }^{1}$, Camille Delville ${ }^{1}$, Penelope Konstantopedos ${ }^{1}$, Davina Derous ${ }^{1}$, \\ Cara L. Green ${ }^{1}$, Yingchun Wang ${ }^{2}$, Jing-Dong J. Han ${ }^{3}$, Daniel E.L. Promislow ${ }^{4}$, Alex \\ Douglas $^{1}$, Luonan Chen ${ }^{5}$, David Lusseau ${ }^{1}$ and John R. Speakman ${ }^{1,2}$ \\ ${ }^{1}$ Institute of Biological and Environmental Sciences, University of Aberdeen, Aberdeen, Scotland, UK \\ 2 State Key Laboratory of Molecular Developmental Biology, Institute of Genetics and Developmental Biology, Chinese \\ Academy of Sciences, Chaoyang, Beijing, China \\ ${ }^{3}$ Key Laboratory of Computational Biology, Chinese Academy of Sciences-Max Planck Partner Institute for Computational \\ Biology, Shanghai Institutes for Biological Sciences, Chinese Academy of Sciences, Shanghai, China \\ ${ }^{4}$ Department of Pathology and Department of Biology, University of Washington, Seattle, Washington, USA \\ ${ }^{5}$ Key Laboratory of Systems Biology, Innovation Center for Cell Signaling Network, Institute of Biochemistry and Cell Biology, \\ Shanghai Institutes for Biological Sciences, Chinese Academy of Sciences, Shanghai, China
}

Correspondence to: John R. Speakman, email: j.speakman@abdn.ac.uk

Keywords: food intake, dietary restriction, protein restriction, calorie restriction, physical activity, Gerotarget

Received: October 30, $2015 \quad$ Accepted: February 28, $2016 \quad$ Published: March 17, 2016

\section{ABSTRACT}

Calorie restriction (CR) delays the onset of age-related disease and extends lifespan in a number of species. When faced with reduced energy supply animals need to lower energy demands, which may be achieved in part by reducing physical activity (PA). We monitored changes in PA using implanted transmitters in male C57BL/6 mice in response to graded levels of CR (10 to $40 \%)$ or matched levels of graded protein restriction (PR) for 3 months. Mice were fed at lights out and ad libitum controls were limited to dark-phase feeding (12AL) or $24 \mathrm{hr} /$ day. Total daily PA declined in a non-linear manner over the first 30 days of CR or PR, remaining stable thereafter. Total daily PA was not related to the level of CR or PR. Total daily PA over the last 20 days of restriction was related to circulating leptin, insulin, tumor necrosis factor-a (TNF- a) and insulin-like growth factor (IGF)-1 levels, measured after 3 months. Mice under restriction showed a high level of activity in the $2 \mathrm{hrs}$ before feeding (food anticipatory activity: FAA). FAA followed a complex pattern, peaking around day 20, falling on day 37 then increasing again. FAA was also positively related to the level of restriction and inversely to leptin, insulin, TNF-a and IGF-1. Non-FAA, in contrast, declined over the period of restriction, generally more so in mice under greater restriction, thereby offsetting to some extent the increase in FAA. Mice under PR displayed no changes in PA over time or in comparison to 12AL, and showed no increase in FAA.

\section{INTRODUCTION}

Calorie restriction (CR), mainly in rodents, but also in lower animals and non-human primates, results in retardation of the aging processes and increased longevity [1-4]. However, in many studies, parallel to the restriction of calories there is a reduction in macronutrient intake, e.g. protein, leading to the suggestion that the beneficial effects of CR may be due to protein restriction (PR) [5-8]. CR leads to alterations in body composition, particularly fat loss [9-11], reductions in adipokines, lowered circulating glucose, insulin and insulin-like growth factor (IGF)-1, leading to subsequent improvements in insulin sensitivity [12-15], lowered body temperature $\left(\mathrm{T}_{b}\right)$ [1617] and alterations in behavior [18, 19]. Many of these physiological characteristics of CR are shared by several 
long lived mutant mouse models, Ames, Snell dwarf, and the growth hormone receptor/binding protein knockout mice [20-22]. In particular a lowered $\mathrm{T}_{\mathrm{b}}$ and improved insulin sensitivity seem important. Experimental reduction of $\mathrm{T}_{\mathrm{b}}$ by overexpressing uncoupling proteins in the brain extended lifespan [23]. In addition in rodents, lower $T_{b}$ was responsible for tumor prevention during $\mathrm{CR}$, while in humans, those with a lower $T_{b}$ had better survival rates than those with a higher $T_{b}[24,25]$. The evolutionarily conserved insulin/IGF-1 signaling pathway (IIS) is strongly implicated in CR-mediated extension of lifespan, with improved insulin sensitivity a key determinant of healthy aging [26, 27]. However while these biomarkers appear to be a pre-requisite for CR's longevity effect, the mechanisms underpinning the beneficial effects of $\mathrm{CR}$ remain unresolved.

To balance a restricted energy intake animals must reduce energy expenditure. There are 4 major components of daily energy expenditure: the energy cost of physical activity (PA), basal metabolic rate (BMR), thermoregulation and the thermic effect of food. BMR comprises a large proportion of energy expenditure and is dependent on both body size and body composition with the contribution of lean mass being greater than fat mass [28]. PA can be divided into spontaneous activity (also referred to as non-exercise activity thermogenesis (NEAT) and voluntary exercise [29]. Spontaneous activity constitutes obligatory survival activity, ie. food searching, while voluntary activity is not directly required for survival [30]. Available literature on the PA response to $\mathrm{CR}$ is contradictory. Despite the reduction in energy intake several rodent studies have shown an increase in PA levels during CR [31-34]. On the other-hand, others have reported a decrease $[35,36]$.

Protocol differences such as diet, genetic background, sex, duration and stringency of restriction may account for the inconsistencies found in the effect of CR on total daily PA in previous studies. For example some studies have considered only PA responses in open field tests [36], while others have measured the energy expended on PA [35], while yet others have focused on total levels of movement [36]. Responses measured by these different methods are not necessarily equivalent. However, consistent across studies is an increase in PA immediately prior to feeding each day (known as food anticipatory activity (FAA)) [37, 38]. FAA is observed in a large variety of species, including insects, fish and primates and appears to be evolutionary conserved (reviewed in [39]). The ability to be physically active and search for food is essential in the wild thus some hypothesize that FAA may be increased foraging behavior to protect against starvation and increase chances of survival $[40,41]$. Increases in activity may be beneficial in the maintenance of health span by counteracting ageing. In humans, exercise evokes a number of health benefits, such as a decreased risk of cardiovascular disease, diabetes and osteoporosis via the maintenance of aerobic capacity, improved bone health and preservation of muscle mass and strength [42-45]. However, increased activity does not appear to be a primary factor behind CR induced longevity. While several rodent studies reported an increase in mean lifespan in response to moderate exercise, unlike CR, no extension in maximum lifespan has been reported [46, 47]. Exercise alone does not increase survival of ad libitum fed animals but attenuated a CR increase in animals subjected to lifelong running [48]. In addition the long-lived Ames dwarf mouse is also less active than wild type controls [49].

PA is under biological control [50] mediated via complex interactions between regulators of energy balance, of which leptin and insulin play a major role [5155]. Leptin and insulin convey energy availability signals to the hypothalamus, a key site for the regulation of energy balance [56-58]. The hypothalamus not only responds to hormonal signals, via leptin and insulin receptors (and others) $[54,59,60]$ but also directly via nutrient related signals, such as glucose and fatty acids (see review [61]), conveying information on available and stored energy supplies. Food availability is known to influence circadian rhythms and these alterations may contribute to the lifeprolonging effect of CR [62] also see review [63]. For instance, $\alpha$ MUPA mice (transgenic mice overproducing the urokinase-type plasminogen activator (UPA) in many brain sites) spontaneously eat less and live longer than wildtype controls but, unlike their controls $\alpha$ MUPA mice can sustain circadian rhythms with age, and this may contribute to their prolonged lifespan [64].

Over a series of papers $[11,15,17,19]$ we have described the diversity of physiological, endocrine, biochemical and behavioral responses to $\mathrm{CR}$, which have been compared to the responses to equivalent levels of PR $[11,15,17]$. Here we will focus on PA and FAA measured via non-invasive, implanted transmitters. We show that non-FAA and FAA appear to be regulated differently in relation to body composition and circulating hormones that, in turn, vary in relation to the CR manipulation.

\section{RESULTS}

\section{Total daily physical activity (PA)}

The level of total daily activity (counts) in relation to the baseline period and the time on CR treatment, averaged across the individuals in each of the CR groups (where food was reduced by 10, 20, 30 and 40\% referred to as $10 \mathrm{CR}, 20 \mathrm{CR}, 30 \mathrm{CR}$ and $40 \mathrm{CR}$ respectively) is illustrated in Figure 1a. During the baseline period there was no significant difference in the total daily PA between the six groups (One-way ANOVA: $\mathrm{F}_{(5,39)}=0.44$, $p=0.816)$, averaging 13356 counts per day $(\mathrm{SD}=2107$, 
Table 1: Parameters of fitted quadratic equations for total daily physical activity (PA).

\begin{tabular}{|c|c|c|c|c|c|}
\hline ID & $\mathbf{a}$ & $\mathbf{b}$ & c & $\mathrm{r}^{2}$ & int \\
\hline 11 & 2.8958 & -209.10 & 11442 & 0.5245 & 36.104 \\
\hline 12 & 5.7121 & -353.37 & 15161 & 0.4791 & 30.932 \\
\hline 13 & 7.2036 & -500.16 & 16958 & 0.6575 & 34.716 \\
\hline 15 & 1.6473 & -161.44 & 15424 & 0.4023 & 49.001 \\
\hline 22 & 4.4976 & -298.95 & 13422 & 0.6574 & 33.234 \\
\hline 40 & 2.9355 & -263.00 & 16173 & 0.5366 & 44.796 \\
\hline 42 & -4.1486 & 138.73 & 12063 & 0.2274 & 16.720 \\
\hline 24AL & & & & Mean & 35.072 \\
\hline 16 & \begin{tabular}{|l|}
-2.5553 \\
\end{tabular} & 102.75 & 11258 & 0.1703 & 20.105 \\
\hline 17 & 2.9416 & 161.77 & 11570 & 0.2704 & 27.497 \\
\hline 18 & 2.9993 & -119.32 & 13808 & 0.1882 & 19.891 \\
\hline 20 & -0.9348 & 18.08 & 11538 & 0.1071 & 9.673 \\
\hline 31 & 4.204 & -223.80 & 13062 & 0.3036 & 26.618 \\
\hline 32 & 3.2787 & -212.01 & 12317 & 0.4117 & 32.331 \\
\hline 38 & 1.6599 & -256.02 & 16601 & 0.6452 & 77.119 \\
\hline 45 & 0.9673 & -160.87 & 16060 & 0.5826 & 83.154 \\
\hline $12 \mathrm{AL}$ & & & & Mean & \begin{tabular}{|l|}
37.049 \\
\end{tabular} \\
\hline 8 & 7.1375 & -413.13 & 12562 & 0.4325 & 28.941 \\
\hline 9 & 2.7444 & -196.80 & 10820 & 0.3623 & 35.855 \\
\hline 21 & 1.3025 & -138.21 & 12973 & 0.3784 & 53.056 \\
\hline 33 & \begin{tabular}{|l|}
-2.1626 \\
\end{tabular} & 64.094 & 13829 & 0.0840 & 14.819 \\
\hline 46 & 2.9308 & -189.32 & 15368 & 0.1294 & 32.298 \\
\hline 50 & -0.6397 & 11.30 & 13895 & 0.0136 & 8.830 \\
\hline 54 & -4.2297 & 120.53 & 13318 & 0.3418 & 14.248 \\
\hline 56 & 1.6864 & -208.65 & 18143 & 0.4781 & 61.863 \\
\hline 10CR & & & & Mean & 31.239 \\
\hline 4 & 3.4194 & -229.39 & 12029 & 0.2937 & 33.542 \\
\hline 10 & 2.6206 & -225.54 & 12552 & 0.6111 & 43.032 \\
\hline 27 & 0.2176 & -90.71 & 13089 & 0.2460 & no fit \\
\hline 37 & 3.904 & -289.08 & 15858 & 0.3910 & 37.024 \\
\hline 39 & 1.5245 & -123.75 & 12006 & 0.1695 & 40.587 \\
\hline 47 & 3.7523 & -303.17 & 15099 & 0.5212 & 40.398 \\
\hline 57 & -0.7709 & -4.29 & 13521 & 0.0918 & no fit \\
\hline 64 & 7.107 & -426.53 & 17413 & 0.3504 & 30.008 \\
\hline 20CR & & & & Mean & \begin{tabular}{|l|}
37.432 \\
\end{tabular} \\
\hline 6 & \begin{tabular}{|l|}
5.6075 \\
\end{tabular} & -390.47 & 17006 & 0.4575 & 34.817 \\
\hline 24 & \begin{tabular}{|l|}
6.2294 \\
\end{tabular} & -410.43 & 13377 & \begin{tabular}{|l|}
0.6775 \\
\end{tabular} & 32.943 \\
\hline 36 & \begin{tabular}{|l|}
-2.449 \\
\end{tabular} & 146.88 & 8671 & \begin{tabular}{|l|}
0.1947 \\
\end{tabular} & 29.988 \\
\hline 49 & 1.9348 & -97.92 & 11605 & 0.0407 & 25.305 \\
\hline 52 & -1.1278 & 28.75 & 11732 & 0.0459 & 12.748 \\
\hline 53 & 4.2078 & -277.57 & 15662 & 0.3773 & 32.983 \\
\hline 30CR & & & & Mean & \begin{tabular}{|l|}
28.131 \\
\end{tabular} \\
\hline 7 & 6.8048 & -552.70 & 19833 & 0.6311 & 40.611 \\
\hline 28 & -3.9962 & 122.87 & 12124 & 0.2658 & 15.373 \\
\hline 30 & -2.5566 & -2.99 & 13343 & 0.5546 & no fit \\
\hline 34 & 0.5291 & -20.17 & 10243 & 0.0038 & 19.063 \\
\hline 44 & -1.0885 & 109.94 & 14965 & 0.0327 & 50.501 \\
\hline
\end{tabular}




\begin{tabular}{|l|l|l|l|l|l|}
\hline 48 & 4.778 & -349.36 & 12417 & 0.6461 & 36.559 \\
\hline 58 & 2.1293 & -148.66 & 5106 & 0.0671 & 34.908 \\
\hline 62 & -3.1711 & 64.47 & 12792 & 0.3091 & 10.165 \\
\hline 40CR & & & & Mean & $\mathbf{2 9 . 5 9 7}$ \\
\hline
\end{tabular}

$y=a \cdot x^{2}+b \cdot x+c$ where $y$ is PA, $x$ is the day of restriction and $a, b$ and $c$ are arbitrary constants. Curves were fitted over the first 40 days of restriction. 10CR, 20CR, 30CR and 40CR signify 10, 20, 30 and $40 \%$ calorie restriction respectively. The $\mathrm{r}^{2}$ of the fitted quadratic equation is shown along with the calculated interpolation point in days (int). Mean interpolation points \pm SD are calculated for each group.

a)

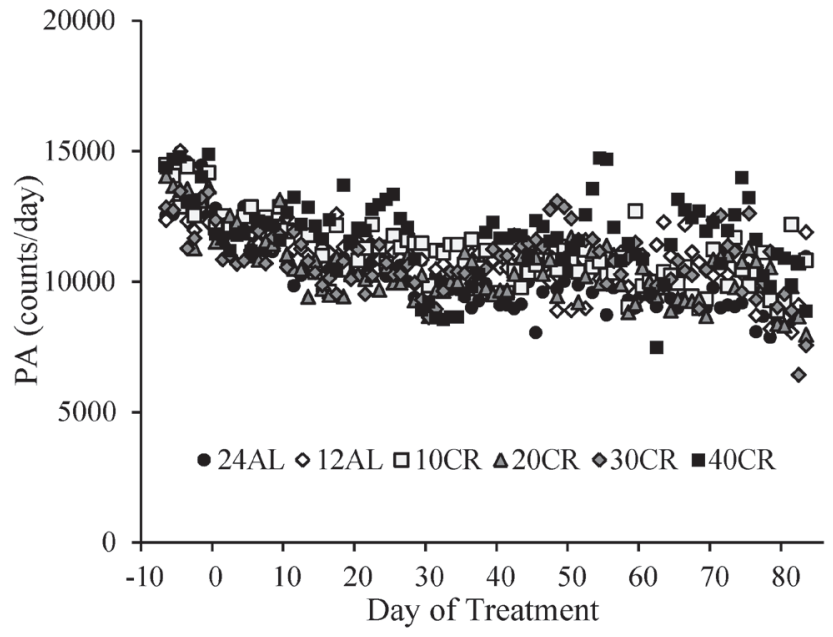

b)

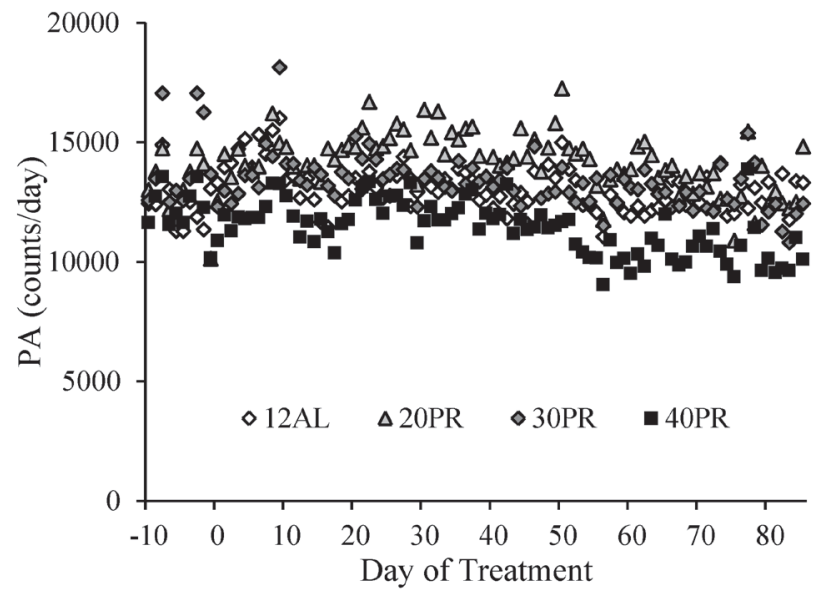

Figure 1: The level of total daily physical activity (PA) in mice under graded levels of a) calorie restriction (CR) or b) protein restriction (PR). The baseline period is represented as negative days -10 to -1. Day 0 denotes the start of the restriction period lasting 84 days. Data was averaged across each of the ad libitum (AL) groups which had access to food for either 24 or $12 \mathrm{hrs} /$ day (24AL and 12AL respectively). Treatment groups were restricted in a graded manner at 10, 20, 30 and 40\% groups of individual baseline food intake (10CR, 20CR, 3CR and 40CR respectively). Diets were isocaloric and protein levels in the 20PR, 30PR and 40PR matched levels of that in the $20 \mathrm{CR}, 30 \mathrm{CR}, 40 \mathrm{CR}$.

a)

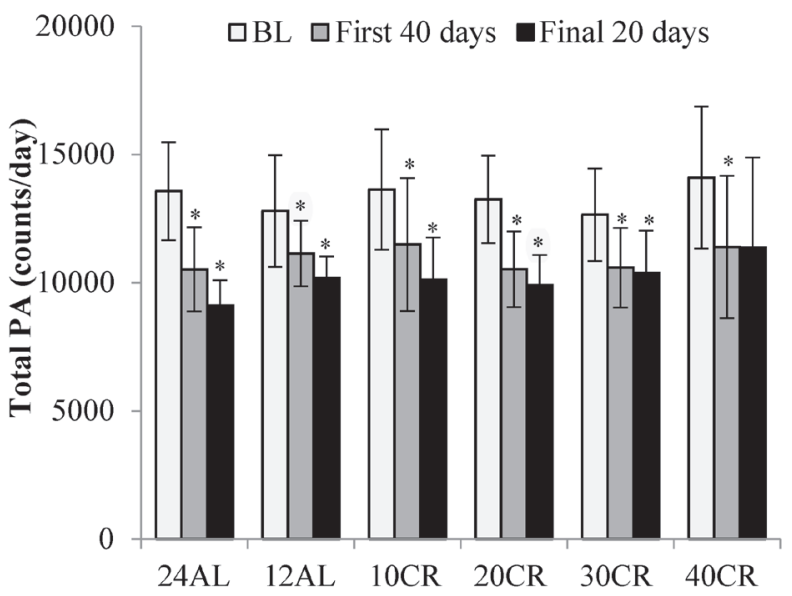

b)

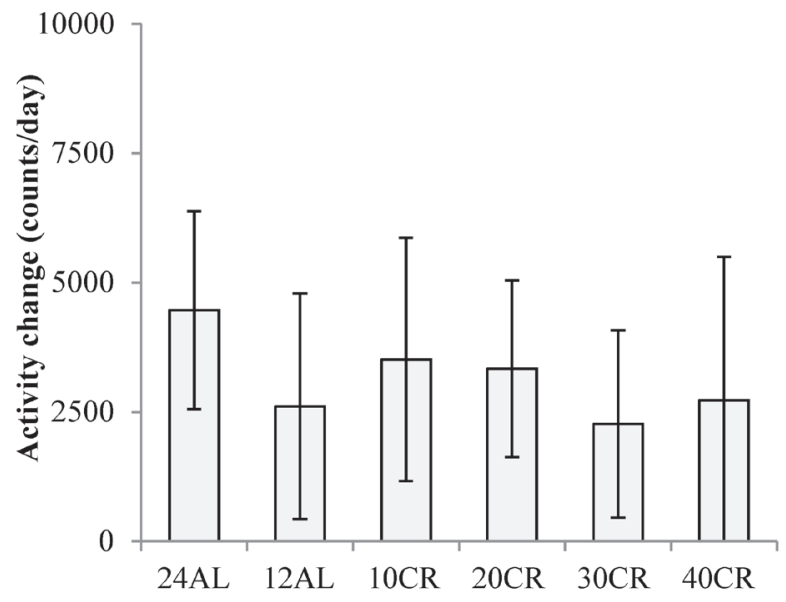

Figure 2: Total daily physical activity (PA) levels. a. Total PA averaged over baseline (BL), the first 40 and the final 20 days of restriction. b. and the overall PA change over entire study period (b). Data shown as mean $\pm \mathrm{SD}$. ${ }^{*}$ significant lower PA compared to BL. 
$n=45$ individuals). Over the first 40 days of restriction daily activity was significantly decreased in all groups (paired comparison within each group: paired $t$-test: $p$ $<0.05$, Figure 2a). The largest reduction was observed in the animals fed ad libitum for 24hr (24AL) (average reduction 3046 counts, ranging +159 to -6243 ) and the least in the 12AL (ad libitum for 12hr) (1655 counts, ranging +624 to -5288 ). The decrease in PA over the first 40 days of restriction was curvilinear. These separate patterns averaged across the individuals for each group are illustrated in Supplementary Figure 1. The best fit (least squares) polynomial regressions to these curves were second order and the parameters of these fits with the predicted inflection points of the curves are presented in Table 1. As the severity of restriction increased, the variance explained by the fitted curves generally declined. There was no significant relationship between the time taken for the curves to reach inflection and the extent of restriction (One-way ANOVA: $\mathrm{F}_{(5,36)}=0.21, p=0.957$ ), taking on average $31.9(\mathrm{SD}=3.6)$ days for the curves to reach their nadirs.

From day 40 the patterns of change in total daily activity levels showed no significant change to the end of study (paired t-tests: $p>0.05$, Supplementary Figure 2). In combination these changes in the total daily activity meant that activity over the last 20 days on restriction was significantly lower than the baseline levels (paired t-tests: $p<0.05$, Figure 2a), in all groups except the 40CR group (paired t-tests: $p=0.128$ ). This was principally because of a large heterogeneity in response in the 40CR group, with 5 individuals reducing activity enormously (maximum decrease $55 \%$ ) while 3 increased activity (maximum increase $25 \%$ ). There was no significant relationship between the extent of restriction and the change in activity over the restriction period (One-way ANOVA: $\mathrm{F}_{(5,39)}=$ $0.75, p=0.34$, Figure $2 \mathrm{~b}$ ) and no relationship between the activity averaged over the last 20 days and the level of restriction (One-way ANOVA: $\mathrm{F}_{(5,39)}=1.14, p=0.34$, average 10212, $\mathrm{SD}=1920$, Figure 2a).

Total daily PA was not significantly related to the amount of body fat (Least squares linear regression (LSR): $\left.\mathrm{r}^{2}=0.072, \mathrm{~F}_{(1,44)}=3.6, p=0.065\right)$ or the levels of structural tissue (pooled mass of carcass, skin and tail; LSR: $\mathrm{r}^{2}=0.055, \mathrm{~F}_{(1,44)}=2.5, p=0.121$ ) (tissue data from [11]). However, there were significant associations between the final levels of activity and the final levels of circulating hormones (hormone data from [15]); leptin (LSR: negative, $\mathrm{r}^{2}=0.232, \mathrm{~F}_{(1,36)}=10.89, p=0.002$, Figure $3 \mathrm{a}$ ), tumor necrosis factor (TNF)- $\alpha$ (LSR: negative, $\mathrm{r}^{2}=0.184, \mathrm{~F}_{(1,39)}=7.92, p=0.008$, Figure $\left.3 \mathrm{~b}\right)$, insulin (LSR: negative, $\mathrm{r}^{2}=0.104, \mathrm{~F}_{(1,36)}=4.19, p=0.048$, Figure 3c) and IGF-1 (LSR: negative $\mathrm{r}^{2}=0.097, \mathrm{~F}_{(1,39)}=4.10$, $p=0.05$, Figure $3 \mathrm{~d}$ ), but not interleukin (IL)-6 (LSR: $\mathrm{r}^{2}$ $\left.=0.025, \mathrm{~F}_{(1,36)}=0.91, p=0.347\right)$ or resistin $\left(\mathrm{LSR}: \mathrm{r}^{2}=\right.$ $\left.0.072, \mathrm{~F}_{(1,36)}=0.26, p=0.612\right)$. When all the available hormone levels were entered as predictors in a multiple regression analysis, both leptin and IL-6 were found to be significant predictors of the level of activity (combined $\mathrm{r}^{2}$ $=0.330$, leptin, $p<0.001$ negative, IL- $6 p=0.03$ positive). Moreover, across all the individuals the average levels of activity were significantly negatively related to the average daily $\mathrm{T}_{\mathrm{b}}$ over the last 20 days (LSR: $\mathrm{r}^{2}=0.180$, $\mathrm{F}_{(1,43)}=10.69, p=0.002$, Figure $\left.3 \mathrm{e}\right)$ and the minimum $\mathrm{T}_{\mathrm{b}}$ over the same final 20 day period (LSR: $\mathrm{r}^{2}=0.112, \mathrm{~F}_{(1,43)}$ $=5.42, p=0.025$, Figure 3f) (temperature data from [17]).

Despite similar levels of total daily PA between the diet groups there was a high variation in time-based patterning over the course of the study (GLM-RM: time $\mathrm{F}_{(3,39)}=22.94, p<0.0005$; Figure 4). Diet or an interaction with time were not significant $\left(\mathrm{F}_{(3,39)}=0.447, p=0.813\right.$ and $\mathrm{F}_{(3,39)}=1.03, p=0.427$, respectively). During the baseline period, when all animals were allowed AL access to food only in the hours of darkness (lights on $0630(0 \mathrm{hr})$, lights off 1830 (12hr), animals followed very similar activity patterns, ie. more active during the dark phase than during the light (Figure 4a). An increase in activity corresponded to the time when mice were weighed and fed prior to lights out (12hr). Activity remained high throughout the period of darkness with a slight lull between 18 and $23 \mathrm{hr}$. A second rise in activity $\sim 22 \mathrm{hr}$ corresponded to lights on and food removal. Once the lights came back on (Ohr) the animals reduced their activity and this low level of activity remained through the rest of the light period. As early as week 1 (Figure $4 \mathrm{~b}$ ) changes in circadian patterns were evident. An increased peak in activity prior to feeding and lights out was recorded in the CR groups, specifically the 40CR (2 fold increase from 735 to 1475). Following food consumption, activity levels dropped to that of baseline levels over the dark phase, rising again $\sim 3$ hours prior to lights on. By week 4, corresponding to the time taken to reach inflection, the pattern of activity in the CR animals was very different with arousal evident in the light phase $\sim$ $7-8 \mathrm{hr}$ (Figure $4 \mathrm{c}$ ). Activity reached peaks of $\sim 2500$ counts/ $\mathrm{hr}$ in the 40CR mice ( $>3$ fold higher than baseline). A clear gradation in these PA patterns was exhibited in the 30CR, 20CR and 10CR mice reaching peaks of 1957, 1416 and 966 counts/hr respectively. In addition, animals under CR dropped their levels of activity in the late dark phase to that of daytime activity, rising again prior to lights on $0 \mathrm{hr}$. Over the 12 weeks of study the daily activity patterns remained similar to that of baseline in the $24 \mathrm{AL}$ and $12 \mathrm{AL}$ animals but the pattern in the $\mathrm{CR}$ animals was very different (Figure 4d). The level of activity declined to the same level as the AL animals once the food was delivered. When the lights are switched on all animals reduced their activity, but around 7-8hrs, when the lights were still on, the activity started to increase. Between 10 and $12 \mathrm{hrs}$, at which time the food was delivered, and the lights were switched off, the mice in the CR groups showed intense activity, higher than at any other time. The intense activity, 2-3 hrs prior to the food being delivered, has been observed previously in mice under restricted feeding 
a)

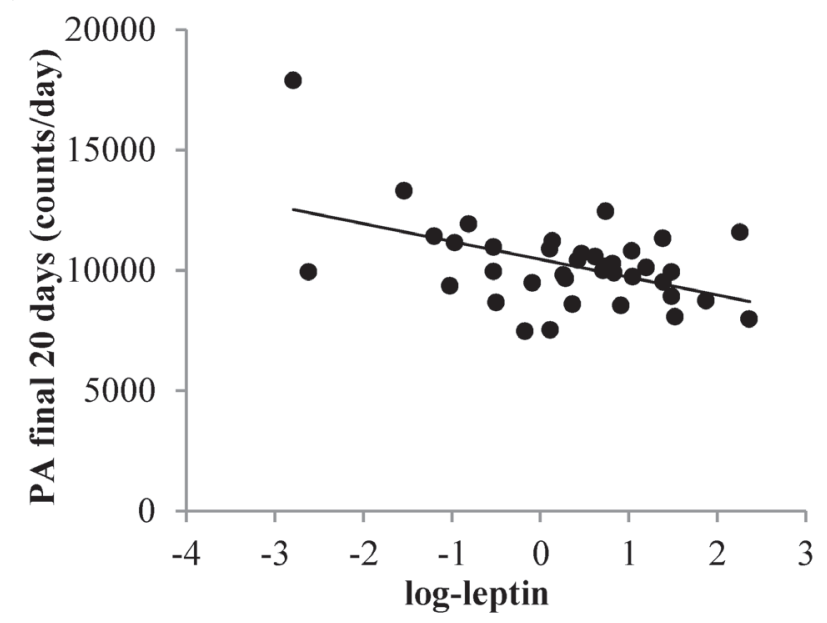

c)

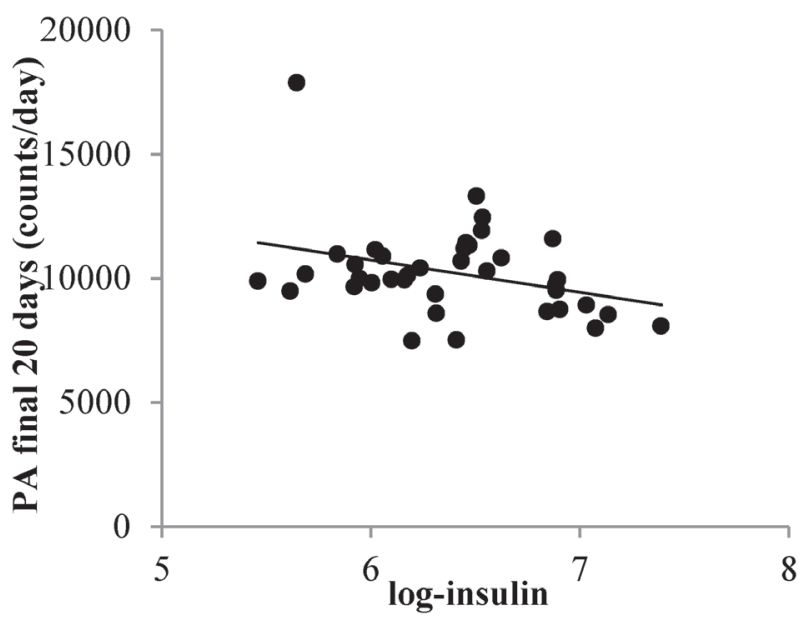

e)

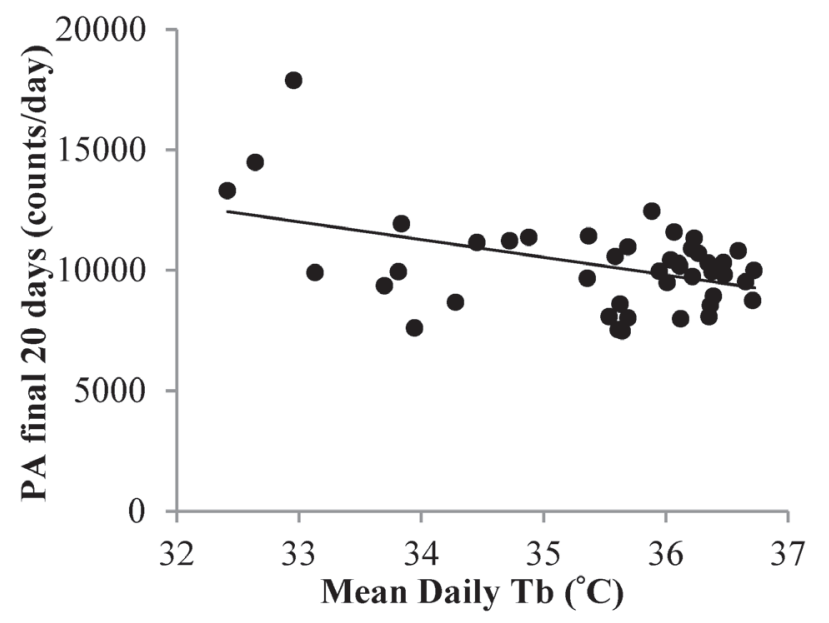

b)

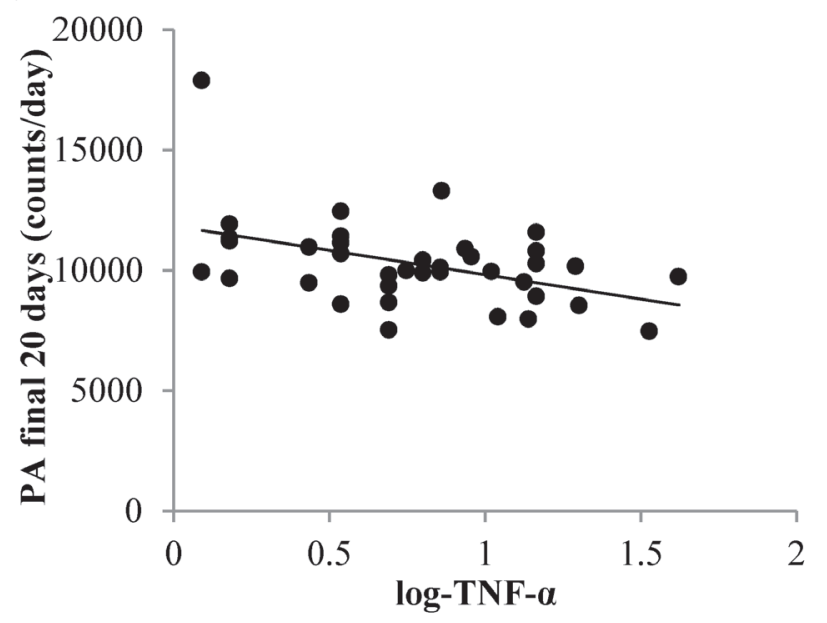

d)

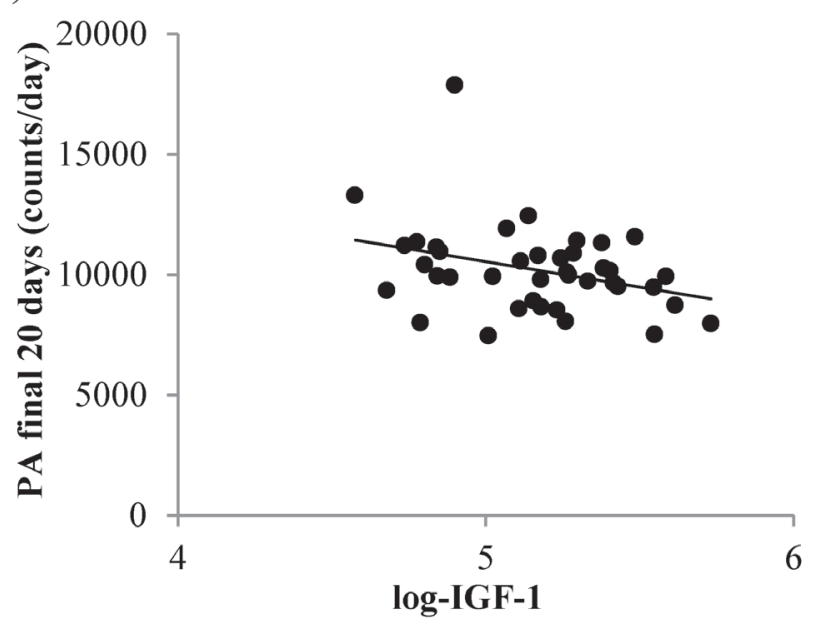

f)

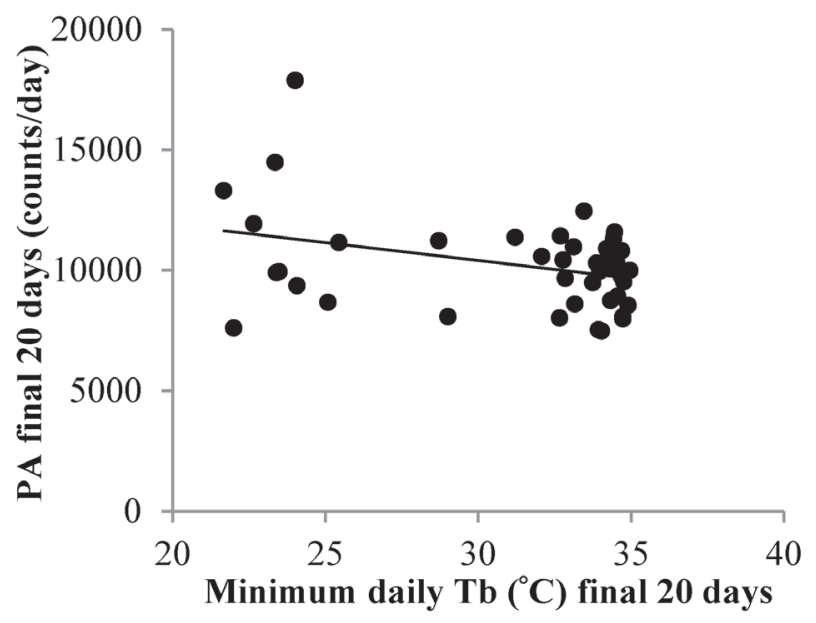

Figure 3: The relationship between the levels of total daily physical activity (PA), measured over the final 20 days of restriction and the levels of circulating hormones and body temperature $\left(\mathbf{T}_{\mathbf{b}}\right)$. $\mathbf{a}$. leptin, $\mathbf{b}$. tumor necrosis factor (TNF)- $\alpha, \mathbf{c}$. insulin, $\mathbf{d}$. insulin growth like factor-1 (IGF-1). e. mean daily $T_{b}$ and f. minimum $T_{b}$. Hormone data is reported in [15] and temperature data taken from [17]. 

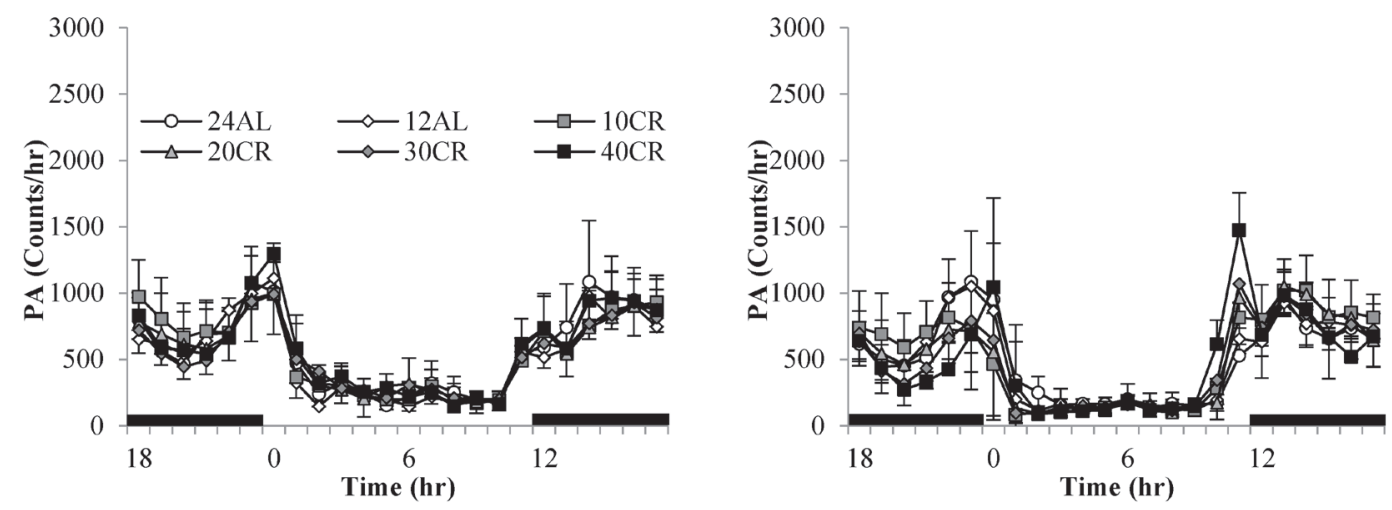

c)

d)
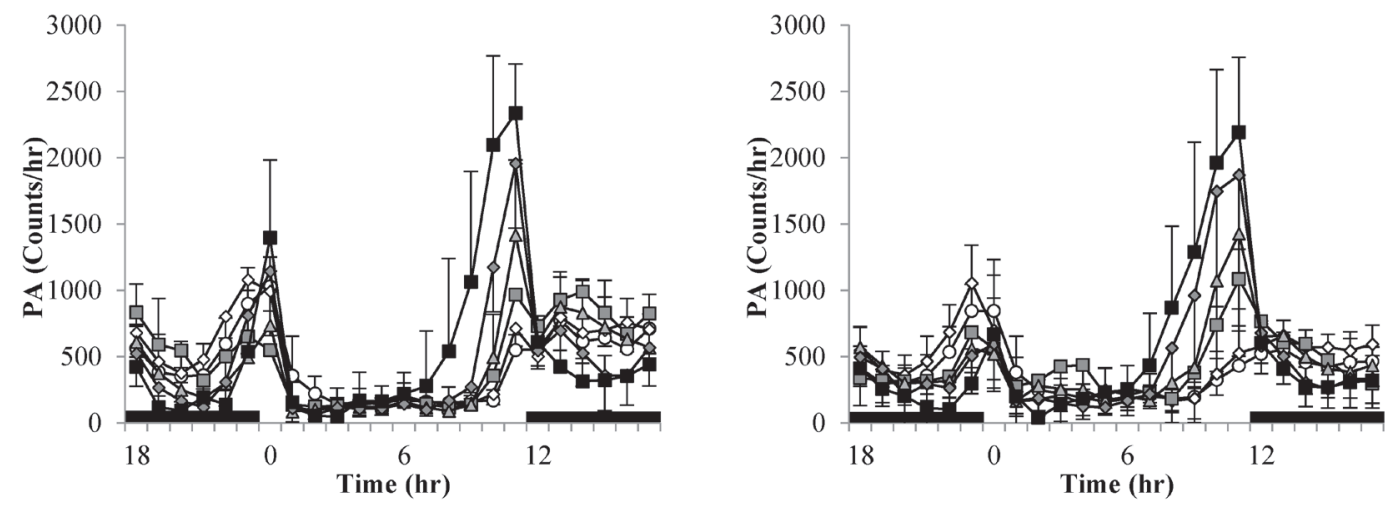

Figure 4: Temporal patterns of physical activity (PA) over a $24 \mathrm{hr}$ period at 4 timepoints over 12 weeks of calorie restriction (CR). a. baseline, b. 1 week of CR c. 4 weeks of CR and d. at the end of study following 11 weeks of CR. Black bars along the $\mathrm{x}$-axis indicate the period of darkness (12-24hrs). Lights are on from 0-12 hrs. CR mice were fed at lights out. 24AL and 12AL represent animals fed ad libitum for 24 and $12 \mathrm{hrs}$ respectively. The 4 treatment groups restricted by 10, 20,30, 40\% are referred to as 10CR, 20CR, $30 \mathrm{CR}$ and $40 \mathrm{CR}$ respectively. Data is presented as mean $\pm \mathrm{SD}$.

a)

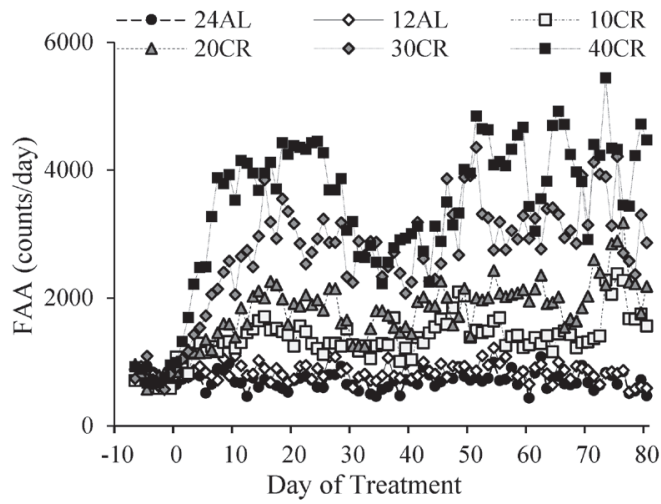

b)

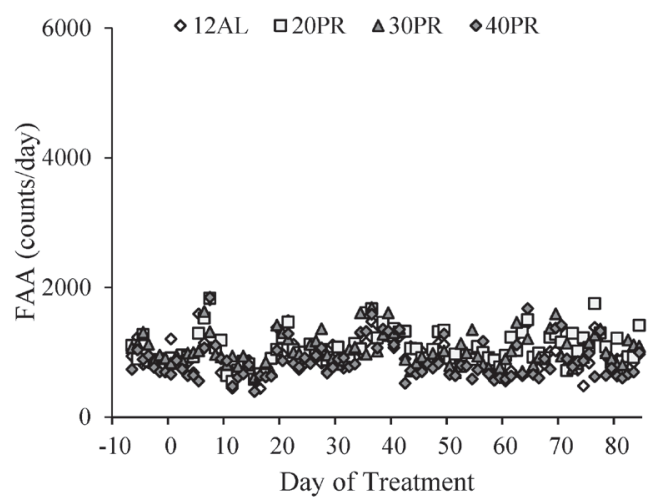

Figure 5: Food anticipatory activity (FAA) measured over entire study in mice under graded levels of a) calorie restriction (CR) or b) protein restriction (PR). Days -10 to -1 indicate the baseline period when all mice were fed ad libitum for 12 hours of dark phase (12AL). D0 represents the start of the restriction period where treatment groups were restricted by $10,20,30$ and $40 \%$ of individual baseline food intake (10CR, 20CR, 3CR and 40CR). An additional AL group received food 24 hours (24AL). Protein levels in the 20PR, 30PR and 40PR matched that of 20CR, 30CR, 40CR. Data was averaged over each group. 
protocols $[65,66]$ and known as food anticipatory activity (FAA). We calculated FAA as the number of counts that occurred in the $2 \mathrm{hr}$ prior to lights out. We then subtracted this from the total daily activity and called this remainder non-FAA. We analyzed these two types of sub-activity separately.

\section{Food anticipatory activity (FAA)}

During the baseline period mice averaged 753 $(\mathrm{SD}=173)$ counts during the 2 hours prior to lights out which was on average $5.7 \%(\mathrm{SD}=1.2)$ of their total daily activity. There was no significant difference between the treatment groups at this stage (One way ANOVA: $\mathrm{F}_{(5,39)}=$ $0.24, p=0.942$ ). FAA started to increase immediately after the treatment started in the CR groups, but not in those under 24AL and 12AL (Figure 5a). By days 15-20 the increase had stabilized and there was a highly significant relationship between the extent of restriction and the level of FAA (One way ANOVA: $\mathrm{F}_{(5,39)}=28.93, p<0.0001$; Figure 6a).

For mice under AL feeding very little change in FAA was recorded after baseline (Figure 6a). In the CR groups FAA at day 15-20 was increased by a factor of 2.2 in the 10CR group, 2.5 in the 20CR animals, 4.9 in the 30CR group and 5.5 fold in the 40CR mice (paired t-tests: $\mathrm{p}<0.05$, Figure 6a). Consequently the percentage of the total daily activity that occurred during the $2 \mathrm{hr}$ period before lights out increased from 5.7\% during baseline in all groups, to $14.7 \%$ at $10 \mathrm{CR}, 19.1 \%$ at $20 \mathrm{CR}, 31.4 \%$ at $30 \mathrm{CR}$ and $35.9 \%$ at $40 \mathrm{CR}$ respectively, between days 15 to 20 (Figure $6 \mathrm{~b}$ ). FAA of the two AL groups was 6.0 and $7.0 \%$ over the same time period.

After day 20 the level of FAA declined (Figure 5a) and hence the $\%$ contribution of this period to total daily activity also declined (Figure 6b). The extent of decline was related to the level of restriction, being greater in the more restricted groups, and was absent in both the groups of AL treated animals. This reduction reached a nadir around day 37, after which the levels of FAA increased again. Over the first 37 days the patterns of FAA were best modelled by quadratic second order polynomials (Figure $6 c)$. The fits and calculated inflection points for these fitted curves are in Table 2. The calculated inflection points in the FAA occurred between 21 and 27 days after restriction started, irrespective of the level of restriction. Between days 50 and the end of the experiment the level of FAA was stable and returned approximately to the level that was observed between days 15 and 20 (Figure 5a \& 6a). Because there was a reduction in total activity between days 15-20 and the end of the experiment (Figure 1a) the $\%$ contributions of FAA to the total were slightly increased over the last 20 days when compared to days 15-20 and were on average $7.6 \%$ at $24 \mathrm{AL}, 7.3 \%$ at $12 \mathrm{AL}, 16 \%$ at $10 \mathrm{CR}, 20.9 \%$ at $20 \mathrm{CR}, 32.4 \%$ at $30 \mathrm{CR}$ and $38.6 \%$ at 40CR (Figure 6b). These levels were highly significantly different between treatment groups (One way ANOVA: $\left.\mathrm{F}_{(5,39)}=25.45, p<0.0005\right)$.

At the individual level final FAA levels were significantly negatively related to the total body fatness (LSR: $\mathrm{r}^{2}=0.672, \mathrm{~F}_{(1,43)}=88.68, p<0.0005$, Figure 7a) and the amount of structural tissue (carcass, skin and tail) at the end of the experiment - day 90 of CR treatment (LSR: $\mathrm{r}^{2}=0.760, \mathrm{~F}_{(1,43)}=136.18, p<0.0005$, Figure $7 \mathrm{~b}$ ) (tissue weights from [11]). In a multiple regression analysis including all the individual organ weights as predictors the only significant predictors of FAA were the carcass weight $(p<0.0005)$ and the mass of the brown adipose tissue (positive association: $\mathrm{T}=2.48, p=0.02$ ). There were also significant associations (negative) between the levels of FAA over the final 20 days and the final levels of circulating hormones (hormone data from [15]: leptin (LSR: $\mathrm{r}^{2}=0.602, \mathrm{~F}_{(1,36)}=54.53, p<0.0005$, Figure 7c), TNF- $\alpha$ (LSR: $\mathrm{r}^{2}=0.286, \mathrm{~F}_{(1,39)}=14.04, p=0.001$, Figure $7 \mathrm{~d}$ ), insulin (LSR: $\mathrm{r}^{2}=0.179, \mathrm{~F}_{(1,36)}=7.87, p=0.008$, Figure 7e) and IGF-1 (LSR: $\mathrm{r}^{2}=0.513, \mathrm{~F}_{(1,39)}=40.1, \mathrm{p}$ $<0.0005$, Figure 7f), but not with IL-6 (LSR: $r^{2}=0.001$, $\left.\mathrm{F}_{(1,36)}=0.04, p=0.848\right)$ or resistin (LSR: $\mathrm{r}^{2}=0.007$, $\left.\mathrm{F}_{(1,36)}=3.00, p=0.092\right)$. When all the measured hormone levels were entered as predictors in a multiple regression analysis both leptin and IGF-1 entered as significant predictors (both negative) of the level of FAA (combined $\mathrm{r}^{2}=0.690$, leptin $p<0.001$, IGF-1 $p=0.003$ ). Average and minimum $\mathrm{T}_{\mathrm{b}}$ over the final 20 days was strongly negatively correlated with FAA (LSR: $\mathrm{r}^{2}=0.853, \mathrm{~F}_{(1,43)}=248.94, p$ $<0.0005$, Figure $7 \mathrm{~g}$ and $\mathrm{r}^{2}=0.769, \mathrm{~F}_{(1,36)}=143.57, p<$ 0.0005 , Figure $7 \mathrm{~h})$, respectively.

\section{Non-FAA}

Subtracting the levels of FAA from the total activity allowed us to investigate the changes in the non-FAA component of the total activity, and therefore to explore whether mice under restriction and demonstrating increased levels of FAA compensated this increase by decreasing their activity at other times of the day. During the baseline period non-FAA comprised the majority of activity in all animals, averaging $94.3 \%$ of the total. The patterns of change in non-FAA are shown in Figure 8a. Non-FAA showed a strong curvilinear decrease over the first 30-40 days of restriction, after which the levels stabilized. We fitted quadratic polynomials to the data for the 7 days of baseline and first 40 days of treatment for all individuals where this was possible ( 1 individual in the $12 \mathrm{AL}$ and 2 in the $10 \mathrm{CR}$ group had non-significant changes and no fit could be made) and calculated the initial rate of decline (at day 0) and the time to inflection of the curves. There was no significant impact of the level of restriction on the time to inflection of the fitted curves (One-way ANOVA: $\mathrm{F}_{(1,39)}=2.17, p=0.080$, Figure 8a). The mean time for the curves to reach a nadir was 35.8 days $(\mathrm{SD}=13.7, n=41)$. However, mice under greater 


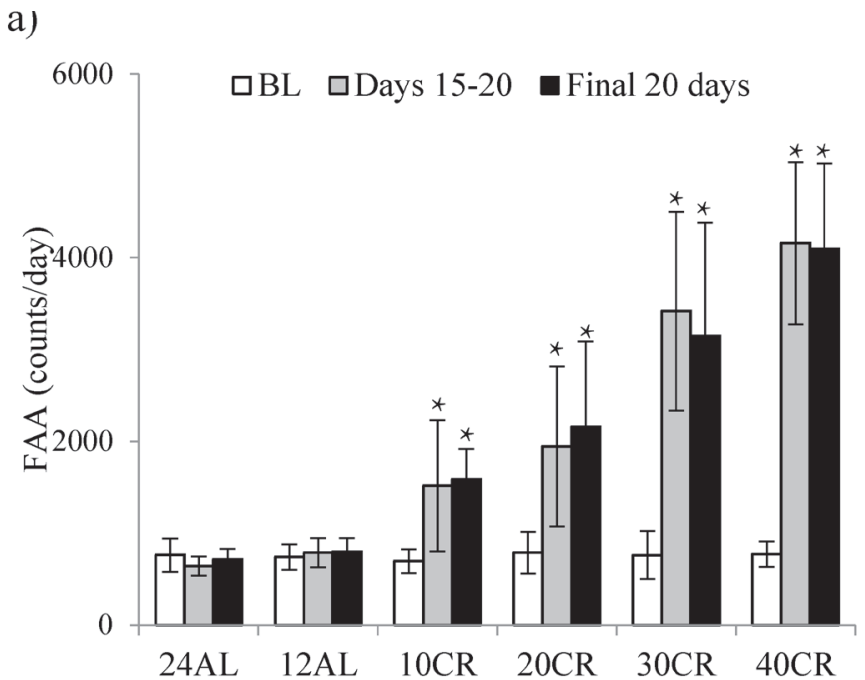

b)

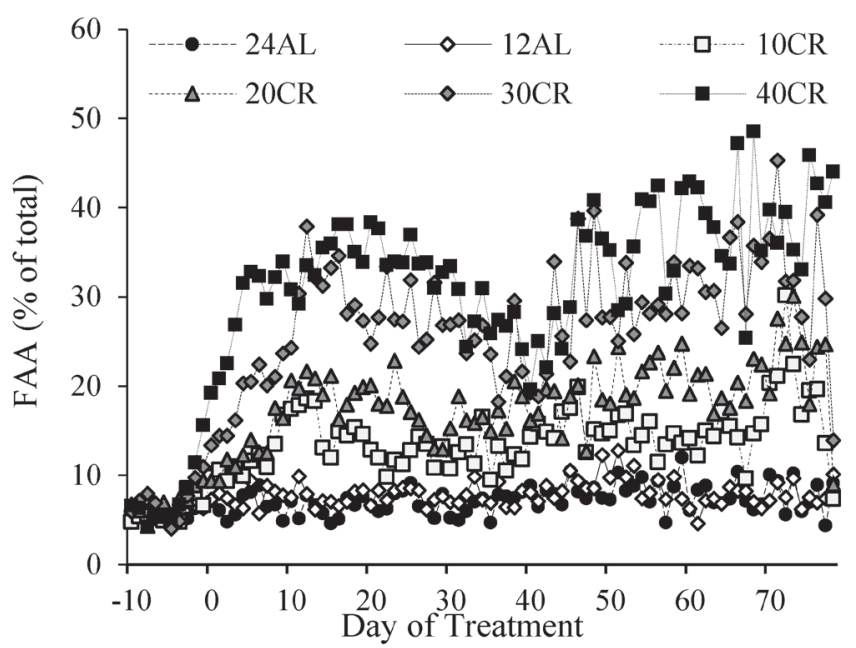

c)

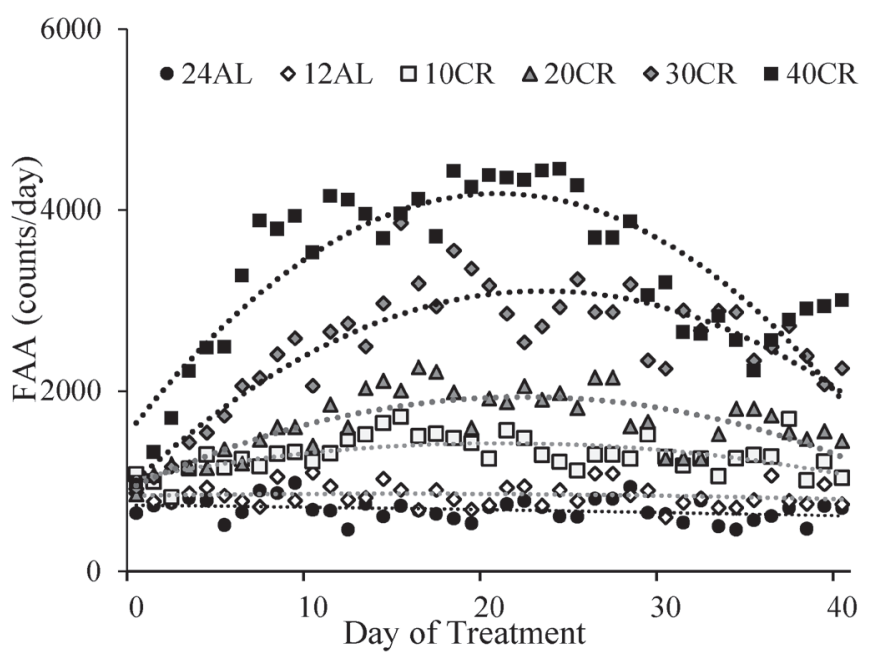

Figure 6: Food anticipatory activity (FAA) measured in C57BL/6 mice under graded levels of calorie restriction (CR). a. FAA at baseline (BL), Days 15-20 and the final 20 days of the study, $\mathbf{b}$. The $\%$ contribution on FAA (averaged over the 2 hrs prior to feeding) to that of total daily physical activity, c. FAA over first 40 days of CR. 10CR, 20CR, 30CR and 40CR represent groups restricted at graded levels of 10, 20,30 and 40\%. 12AL and 24AL represent 12 and $24 \mathrm{hr}$ ad libitum fed groups. Data presented as mean $\pm \mathrm{SD}$ with ${ }^{*}$ denoting significant increases in FAA compared to BL. 
a)

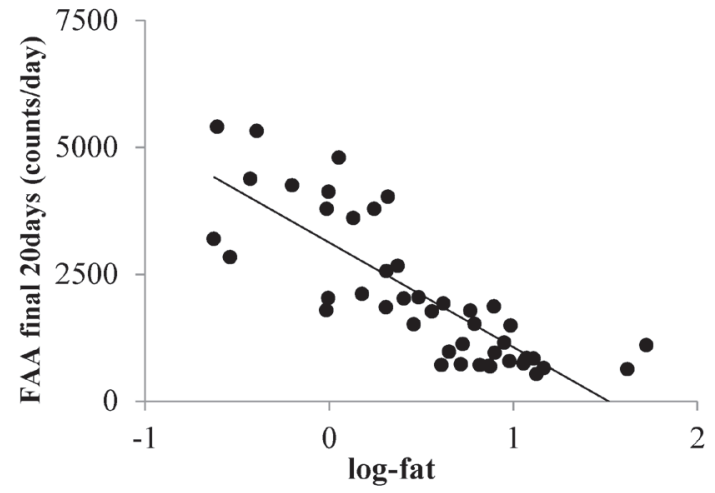

c)

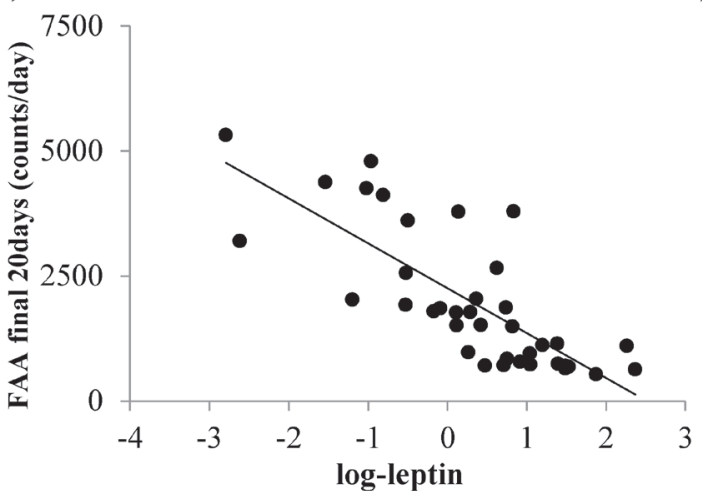

e)

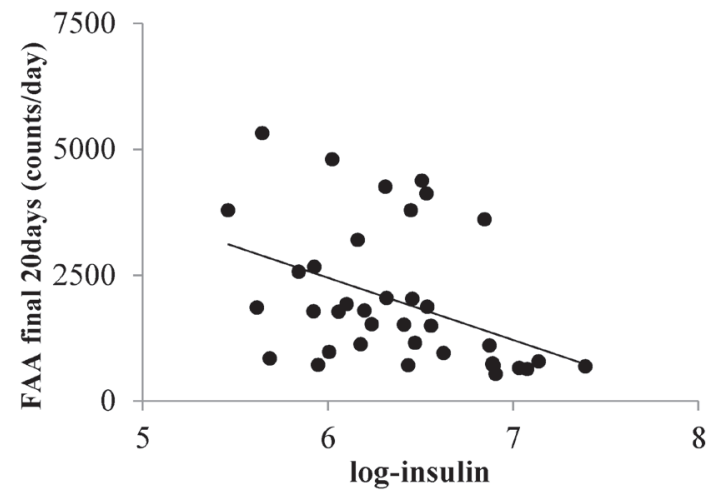

g)

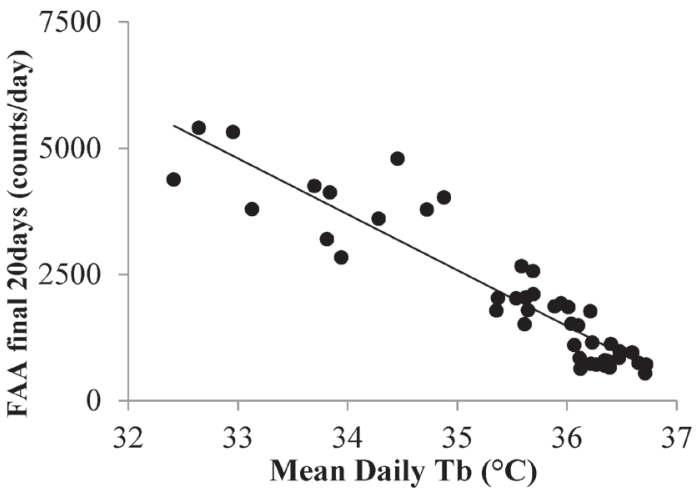

f) b)

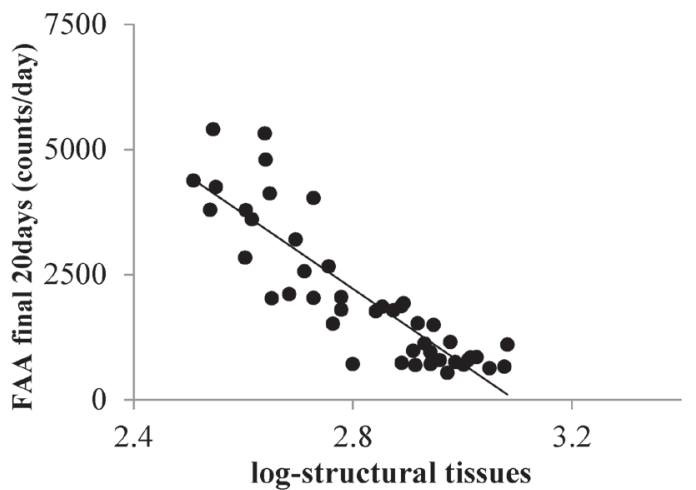

d)
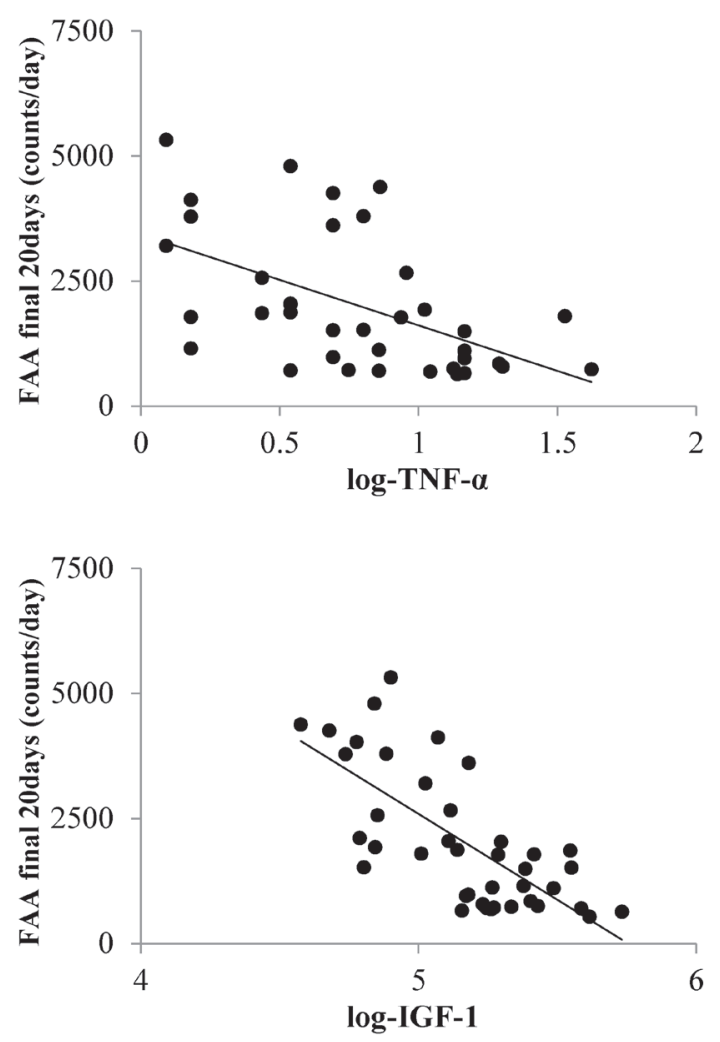

h)

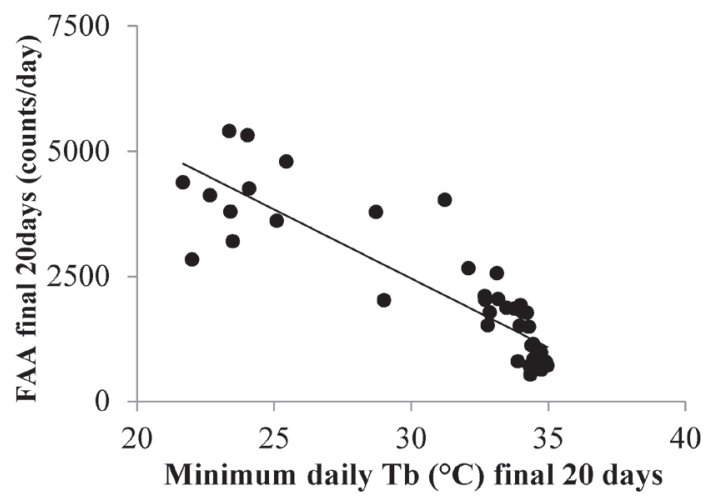

Figure 7: Significant associations between the levels of food anticipatory activity (FAA) averaged over the final 20 days of restriction and body composition, levels of circulating hormones and body temperature $\left(T_{b}\right)$. a. body fat, $b$. structural tissues, $\mathbf{c}$. leptin, $\mathbf{d}$. tumor necrosis factor (TNF)- $\alpha$, e. insulin, $\mathbf{f}$. insulin growth factor (IGF)-1, g. mean daily $\mathrm{T}_{\mathrm{b}}$ and $\mathbf{h}$. minimum $\mathrm{T}_{\mathrm{b}}$. Body composition data from [11], hormone data from [15] and $\mathrm{T}_{\mathrm{b}}$ data from [17]. 
levels of restriction had a significantly faster rate of initial decline in non-FAA (One-way ANOVA: $\mathrm{F}_{(1,39)}=2.45, p$ $=0.05$, Figure $9 \mathrm{a})$. Hence the initial rate of decline in the 12AL group averaged 43 counts per day while in the 40CR group it was almost 3 times higher at 126 counts (post-hoc Tukey $p<0.022$ ). Despite differences in rate of decline, the average level of non-FAA over the first 40 days of the treatment was similar between groups (One-way ANOVA: $\left.\mathrm{F}_{(1,39)}=2.45, p=0.074\right)$ and remained similar over the last 20 days of study (One-way ANOVA: $\mathrm{F}_{(1,39)}=2.27, p=$

a)

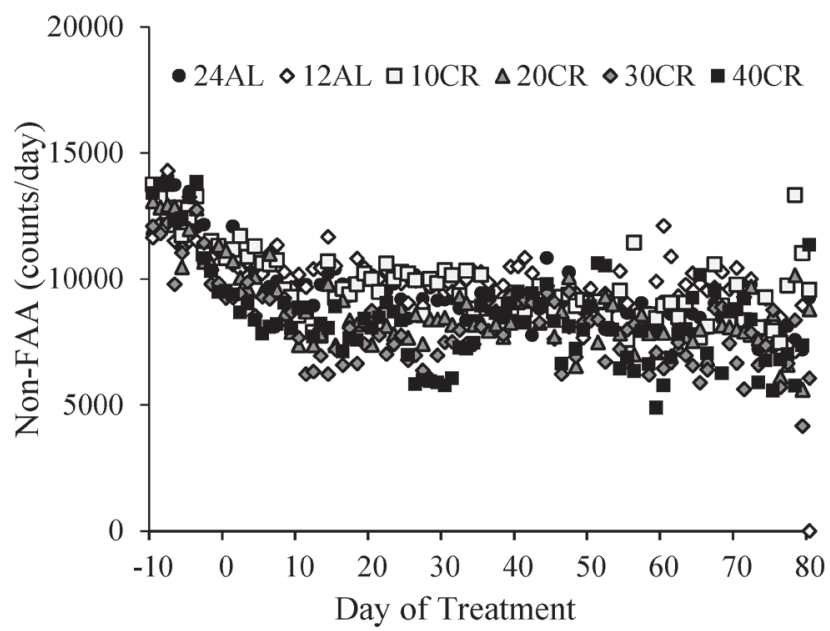

0.067, Figure 9b).

Non-FAA over the last 20 days of the experiment was related positively to the final BM of the mice (LSR: $\left.\mathrm{r}^{2}=0.016, \mathrm{~F}_{(1.43)}=8.52, p=0.006\right)$ specifically, body fat (LSR: $\mathrm{r}^{2}=0.129, \mathrm{~F}_{(1,43)}=6.4, p=0.015$ ) and structural tissues (LSR: $\mathrm{r}^{2}=0.205, \mathrm{~F}_{(1,43)}=11.08, p=0.002$ ). There was no significant relationship between the level of nonFAA over the last 20 days of the experiment and the circulating levels of leptin (LSR: $\mathrm{r}^{2}=0.018, \mathrm{~F}_{(1,36)}=0.66, p$ $=0.421)$, TNF- $\alpha\left(\right.$ LSR: $\left.r^{2}=0.003, \mathrm{~F}_{(1,35)}=0.01, p=0.913\right)$,

b)

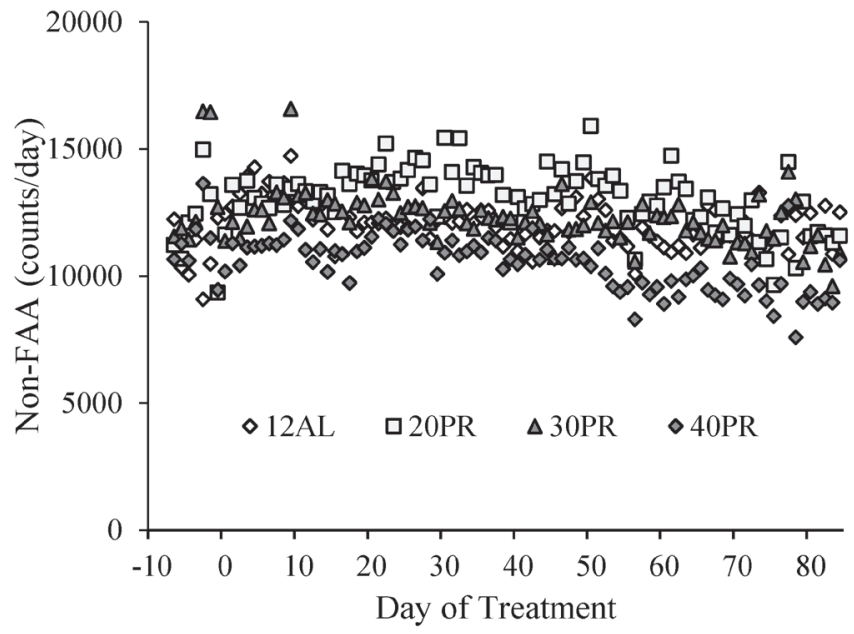

Figure 8: The level of non-food anticipatory activity (non-FAA) in mice under graded levels of a) calorie restriction (CR) or b) protein restriction (PR). Negative days -10 to -1 indicate the baseline period while Day 0 denotes the start of the restriction period. Data was averaged across each of the ad libitum (AL) groups which had access to food for either 24 or $12 \mathrm{hrs} / \mathrm{day}$ (24AL and 12AL respectively). Treatment groups were restricted in a graded manner at 10, 20, 30 and 40\% groups of individual baseline food intake (10CR, 20CR, 3CR and 40CR). Protein levels of the 20PR, 30PR and 40PR matched that in the 20CR, 30CR, 40CR.

a)

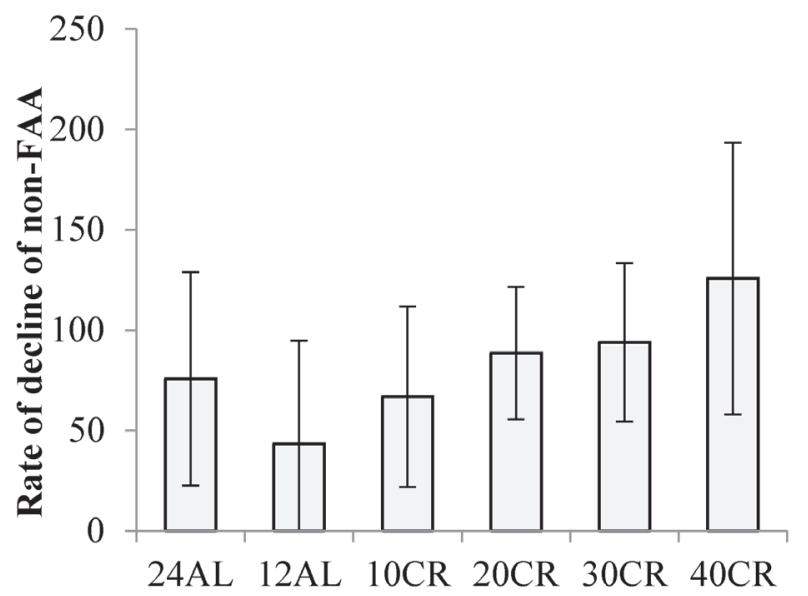

b)

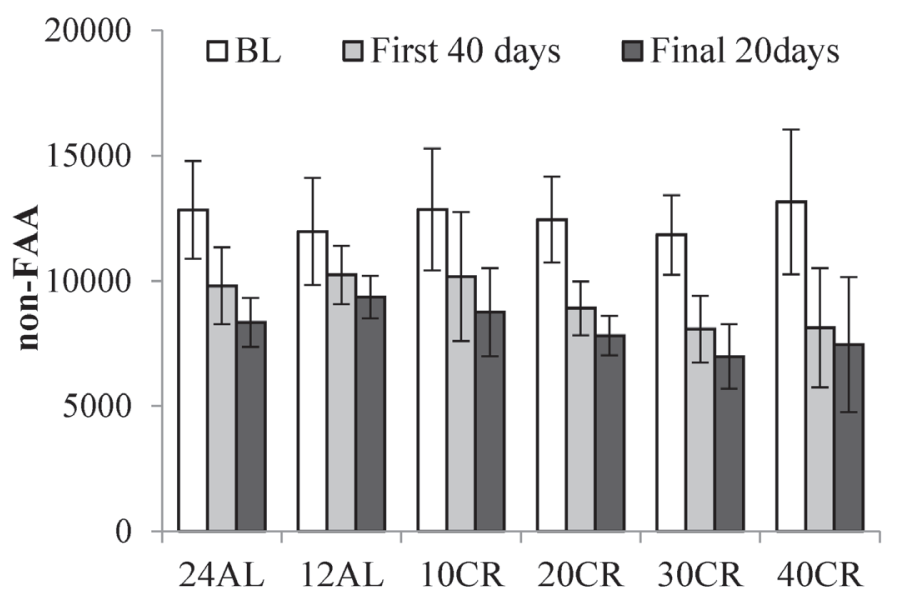

Figure 9: Non-food anticipatory activity (non-FAA) in mice under graded levels of calorie restriction (CR). a. the rate of decline of non-FAA and b. non-FAA measured at baseline (BL), the first 40 and the final 20 days of restriction. Non-FAA was calculated from subtraction of FAA from total daily physical activity. Restriction levels were set at 10\%, 20\%, 30\% and 40\% (10CR, 20CR, 3CR and 40CR respectively). 12AL and $24 \mathrm{AL}$ represent $12 \mathrm{hr}$ and $24 \mathrm{hr}$ ad libitum fed groups. Data shown as mean $\pm \mathrm{SD}$ and ${ }^{*}$ shows significant difference in comparison to BL levels of non-FAA. 
Table 2: Parameters of fitted quadratic equations for food anticipatory activity (FAA).

\begin{tabular}{|c|c|c|c|c|c|}
\hline TID & $\mathbf{a}$ & b & c & $\mathbf{r}^{2}$ & int \\
\hline 11 & 0.071 & -6.29 & 759.52 & 0.012 & 44.27 \\
\hline 12 & 0.290 & -24.20 & 1051.70 & 0.177 & 41.68 \\
\hline 13 & 0.053 & -6.12 & 655.89 & 0.053 & 58.30 \\
\hline 15 & -0.438 & 16.00 & 820.40 & 0.080 & 18.25 \\
\hline 22 & -0.265 & 8.06 & 650.52 & 0.064 & 15.21 \\
\hline 40 & -0.070 & 1.50 & $803 . .85$ & 0.007 & 10.70 \\
\hline 42 & 0.357 & -10.70 & 645.68 & 0.124 & 15.00 \\
\hline 24AL & & & & Mean & 29.06 \\
\hline 16 & -0.673 & 32.72 & 490.71 & 0.260 & 24.30 \\
\hline 17 & -0.072 & 1.40 & 842.99 & 0.010 & 9.75 \\
\hline 18 & -0.521 & 31.07 & 569.28 & 0.098 & 29.84 \\
\hline 20 & -0.566 & 34.10 & 527.63 & 0.119 & 30.12 \\
\hline 31 & -0.108 & 5.15 & 751.28 & 0.003 & 23.78 \\
\hline 32 & -0.060 & 1.82 & 681.93 & 0.007 & 15.14 \\
\hline 38 & 0.224 & -11.11 & 788.83 & 0.028 & 24.83 \\
\hline 45 & 0.229 & -13.14 & 1171.50 & 0.012 & 28.75 \\
\hline $12 \mathrm{AL}$ & & & & Mean & 23.31 \\
\hline 8 & -1.215 & 69.61 & 329.86 & 0.317 & 28.64 \\
\hline 9 & -2.163 & 118.71 & 260.18 & 0.444 & 27.44 \\
\hline 21 & -0.362 & 21.25 & 624.58 & 0.053 & 29.34 \\
\hline 33 & -0.464 & 32.78 & 703.73 & 0.230 & 35.33 \\
\hline 46 & -0.443 & 34.17 & 504.84 & 0.192 & 38.53 \\
\hline 50 & -0.307 & 21.38 & 661.80 & 0.072 & 34.82 \\
\hline 54 & -1.587 & 92.18 & 617.72 & 0.285 & 29.05 \\
\hline 56 & -2.016 & 104.44 & 528.94 & 0.332 & 25.91 \\
\hline 10CR & & & & Mean & 31.13 \\
\hline 4 & -0.224 & 27.98 & 626.68 & 0.348 & 62.53 \\
\hline 10 & -0.766 & 54.56 & 356.92 & 0.431 & 35.60 \\
\hline 27 & -2.385 & 139.27 & 512.90 & 0.377 & 29.20 \\
\hline 37 & -0.694 & 35.87 & 1173.70 & 0.092 & 25.86 \\
\hline 39 & -0.979 & 52.39 & 458.70 & 0.242 & 26.75 \\
\hline 47 & -0.841 & 52.12 & 536.00 & 0.228 & 31.00 \\
\hline 57 & -3.422 & 203.37 & -155.53 & 0.600 & 29.71 \\
\hline 64 & -3.720 & 211.59 & -134.16 & 0.643 & 28.44 \\
\hline 20CR & & & & Mean & 33.64 \\
\hline 6 & -2.824 & 184.12 & 695.50 & 0.386 & 32.60 \\
\hline 24 & -1.976 & 121.09 & 156.59 & 0.428 & 30.64 \\
\hline 36 & -4.626 & 271.50 & -592.30 & 0.593 & 29.35 \\
\hline 49 & -3.392 & 209.95 & -148.00 & 0.525 & 30.95 \\
\hline 52 & -3.656 & 250.68 & -503.29 & 0.603 & 34.28 \\
\hline 53 & -1.464 & 94.94 & 381.12 & 0.548 & 32.43 \\
\hline $30 \mathrm{CR}$ & & & & Mean & 31.71 \\
\hline 7 & -4.620 & 261.34 & 134.65 & 0.504 & 28.28 \\
\hline 28 & -5.646 & 318.78 & 18.51 & 0.473 & 28.23 \\
\hline 30 & -5.471 & 327.29 & -473.36 & 0.606 & 29.91 \\
\hline 34 & -5.577 & 316.51 & -629.11 & 0.506 & 28.38 \\
\hline 44 & -6.017 & 353.38 & -585.35 & 0.519 & 29.37 \\
\hline 48 & -3.227 & 182.83 & 52.63 & 0.696 & 28.33 \\
\hline 58 & -5.993 & 344.46 & -530.43 & 0.534 & 28.74 \\
\hline 62 & -6.562 & 353.74 & -409.20 & 0.727 & 26.95 \\
\hline 40CR & & & & Mean & 28.52 \\
\hline
\end{tabular}

$y=a \cdot x^{2}+b \cdot x+c$ where $y$ is FAA, $x$ is the day of restriction and $a, b$ and $c$ are arbitrary constants. Curves were fitted over the first 40 days of restriction. 10CR, 20CR, 30CR and 40CR signify 10, 20, 30 and 40\% calorie restriction respectively. The $\mathrm{r}^{2}$ of the fitted quadratic equation is shown along with the calculated interpolation point in days (int). Mean interpolation points are calculated for each group. 
Table 3: Average daily physical activity (PA), food anticipatory activity (FAA) and non-FAA in animals under protein restriction (PR).

\begin{tabular}{|c|c|c|c|c|c|c|}
\hline Diet & \multicolumn{2}{|l|}{ Total-PA } & \multicolumn{2}{|l|}{ FAA } & \multicolumn{2}{|l|}{ Non-FAA } \\
\hline & BL & FL & BL & FL & BL & FL \\
\hline 12AL & $12405 \pm 158$ & $12592 \pm 1827$ & $875 \pm 101$ & $910 \pm 137$ & $11307 \pm 263$ & $11668 \pm 1699$ \\
\hline 20PR & $13117 \pm 2238$ & $13312 \pm 2563$ & $937 \pm 247$ & $1093 \pm 254$ & $12147 \pm 2152$ & $12140 \pm 2464$ \\
\hline 30PR & $14149 \pm 2920$ & $12678 \pm 1584$ & $1052 \pm 166$ & $1017 \pm 276$ & $13177 \pm 2928$ & $11582 \pm 1653$ \\
\hline 40PR & $12186 \pm 1175$ & $10511 \pm 872$ & $816 \pm 71$ & $860 \pm 105$ & $11302 \pm 1137$ & $9532 \pm 1025$ \\
\hline
\end{tabular}

PR was graded at 20,30 and 40\% (20PR, 30PR and 40PR respectively). PR was started at 20weeks old for the duration of 3 months. Data shown as average \pm SD counts /day and counts /hr for FAA. No significant differences were found between groups at any time point or within groups when baseline (BL) values were compared to final values at the end of the study (FL).

Table 4: Morphological and hormonal relationships between average daily physical activity (PA), food anticipatory activity (FAA) and non-FAA in animals under protein restriction (PR).

\begin{tabular}{|l|l|l|l|l|l|l|}
\hline Diet & Total-PA & \multicolumn{3}{l}{ FAA } & \multicolumn{2}{l|}{ Non-FAA } \\
\hline & T & $\mathbf{p}$ & T & $\mathbf{p}$ & T & p \\
\hline FM & -2.17 & 0.048 & -0.01 & 0.990 & -0.01 & 0.992 \\
\hline St.Tiss & -1.83 & 0.088 & 0.31 & 0.761 & -0.06 & 0.957 \\
\hline Leptin & -3.35 & 0.005 & -1.14 & 0.272 & -1.09 & 0.298 \\
\hline Insulin & -2.04 & 0.064 & -2.64 & 0.021 & -1.11 & 0.293 \\
\hline IGF-1 & -1.35 & 0.197 & 0.12 & 0.909 & 0.62 & 0.544 \\
\hline Av Tb & -0.35 & 0.734 & -0.94 & 0.366 & -0.53 & 0.608 \\
\hline
\end{tabular}

PR was started at 20weeks old for the duration of 3 months with PR graded at 20, 30 and 40\% (20PR, 30PR and 40PR respectively). FM = fat mass, $\mathrm{St}$.Tiss = structural tissues, IGF-1 = insulin-like growth factor $1, \mathrm{Av} \mathrm{Tb}=$ average body temperature.

insulin (LSR: $\left.\mathrm{r}^{2}=0.02, \mathrm{~F}_{(1,36)}=0.01, p=0.928\right)$, IGF-1 (LSR: $\left.\mathrm{r}^{2}=0.006, \mathrm{~F}_{(1,39)}=2.43, p=0.128\right)$, IL-6 (LSR: $\left.\mathrm{r}^{2}=0.048, \mathrm{~F}_{(1,36)}=1.81, \mathrm{p}=0.187\right)$ or resistin (LSR: $\mathrm{r}^{2}=$ $\left.0.085, \mathrm{~F}_{(1,36)}=0.31, p=0.582\right)$. Across all the individuals there was no significant relationship between the level of FAA and the level of non-FAA (LSR: $\mathrm{r}^{2}=0.055, \mathrm{~F}_{(1,43)}=$ $2.49, p=0.122$, Figure 10). The absence of a significant relationship was heavily influenced by three mice from 40CR group that had both high non-FAA and FAA (as indicated by arrows in Figure 10). If these three data were excluded then among the remaining individuals there was a strong negative relationship of non-FAA to FAA, when both were averaged over the last 20 days of the experiment $\left(\mathrm{r}^{2}=0.37, \mathrm{~F}_{(1,40)}=23.52, p<0.0005\right)$.

\section{Protein restriction (PR)}

\section{Total daily physical activity (PA)}

There were no differences is total daily PA between any of the groups over the baseline period, during which time all mice were fed the same diet (average 12986 counts/day, $\mathrm{SD}=1901$; One-way ANOVA: $\mathrm{F}_{(3,10)}=0.59$, $p=0.635$, Figure $1 \mathrm{~b}$ and Table 3 ). The level of total daily PA did not change over the course of the PR treatment with no evidence of an impact of PR (GLM-RM: time $\mathrm{F}_{(1,14)}=0.670, p=0.427$, diet $\mathrm{F}_{(1,14)}=0.284, p=0.603$, or interaction between the two factors $\mathrm{F}_{(1,14)}=0.346, p$ $=0.566$, Figure $1 \mathrm{~b}$ ). The hourly patterns of PA over the course of the study are shown in Figure 11. All groups of 
a)

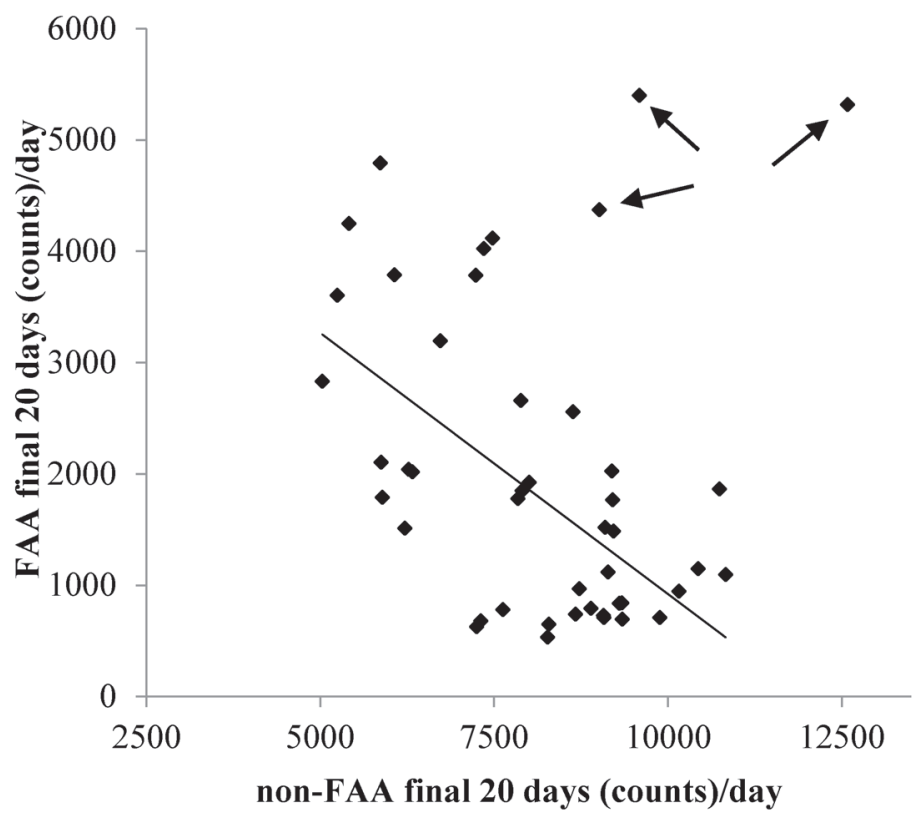

Figure 10: The relationship between non-food anticipatory activity (non-FAA) and FAA over the final 20days of restriction. The trend line symbolizes the strong negative relationship between non-FAA to FAA when 3 individuals from 40CR group with high non-FAA and FAA (indicated by arrows) were removed.

a)

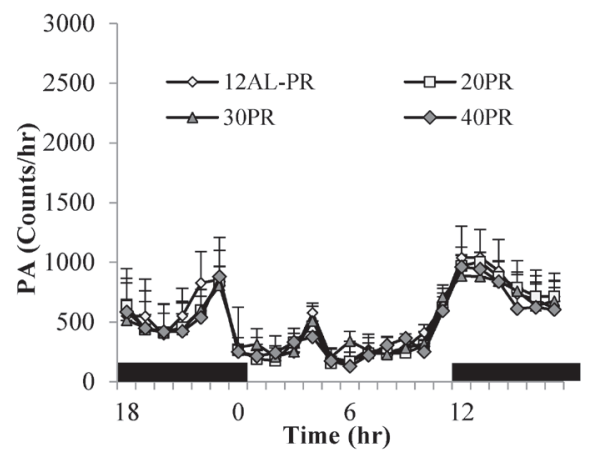

c)

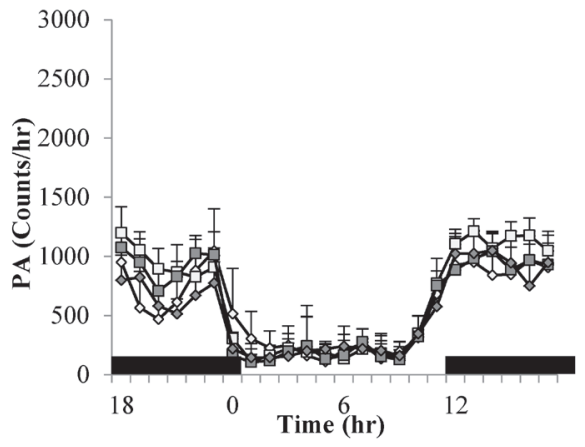

b)

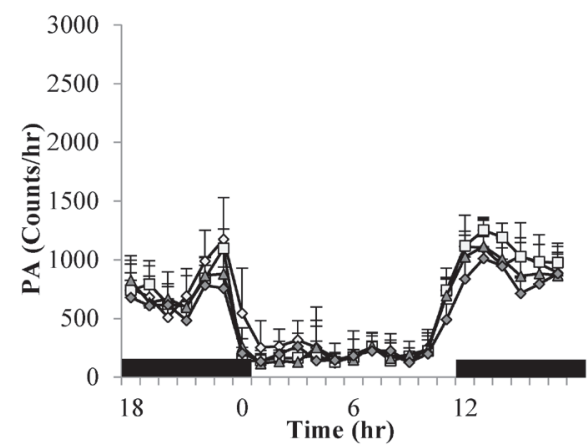

d)

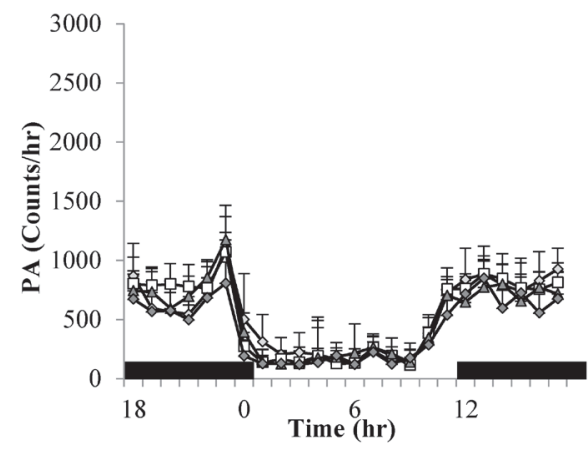

Figure 11: Physical activity (PA) shown over a $24 \mathrm{hr}$ period at 4 timepoints over 12 weeks of protein restriction (PR). a. baseline, b. 1 week $\mathbf{c}$. 4 weeks and d. and 11 weeks of PR. Mice were fed at lights out (12hr) as indicated by black bars along the $\mathrm{x}$-axis. $12 \mathrm{AL}$ represent animals fed ad libitum for $12 \mathrm{hrs}$. 20PR, 30PR and 40PR refers to animals were diet was restricted by $20,30,40 \%$ protein without the reduction in calories. Data is presented as mean $\pm \mathrm{SD}$. 
animals displayed very clear and comparable, nocturnal activity, low over the light phase, rising prior to lights out, at which time the mice are weighed and fed. A very similar pattern was evident over the 4 time points analyzed; the baseline period (Figure 11a and Table 3a), after 1 week of treatment (Figure 11b), after 4 weeks of treatment (Figure 11c) and at the end of the study (Figure 11d and Table 3a).

Total daily PA over the last 20 days of the experiment was related to body fat (LSR: $\mathrm{r}^{2}=0.252, \mathrm{~F}_{(1,14)}$ $=4.71, p=0.048$, Figure 12a) but not the structural tissues (LSR: $\mathrm{r}^{2}=0.193, \mathrm{~F}_{(1,14)}=3.35, p=0.088$ ) or vital organs (LSR: $\left.\mathrm{r}^{2}=0.224, \mathrm{~F}_{(1,14)}=4.05, p=0.064\right)$. A significant relationship was found between total daily PA over the last 20 days and leptin (LSR: $\mathrm{r}^{2}=0.449, \mathrm{~F}_{(1,14)}=11.22$, $p=0.005$, Figure 12b) but not insulin (LSR: $\mathrm{r}^{2}=0.257$, $\left.\mathrm{F}_{(1,14)}=4.14, p=0.064\right)$ or IGF-1 (LSR: $\mathrm{r}^{2}=0.116, \mathrm{~F}_{(1,14)}$ $=1.83, p=0.197)$. In addition, total daily PA was not associated with average body temperature recorded at the end of study (LSR: $\left.\mathrm{r}^{2}=0.008, \mathrm{~F}_{(1,14)}=0.12, p=0.734\right)$. A summary of all relationships is shown in Table 4.

\section{Food anticipatory activity (FAA)}

No differences in FAA counts, averaged over the baseline period, were observed between all groups or in comparison to FAA averaged over the final 20 days of study (paired $t$-test: $\mathrm{t}_{15}=2.15, p<0.051$, Figure $5 \mathrm{~b}$ ). The change in FAA ranged from +2 to -298 , comprising 7.1 and $8 \%$ of total activity at baseline and the final 20 days of study, respectively. The level of FAA over the final 20 days of study was not related to body composition or

a)

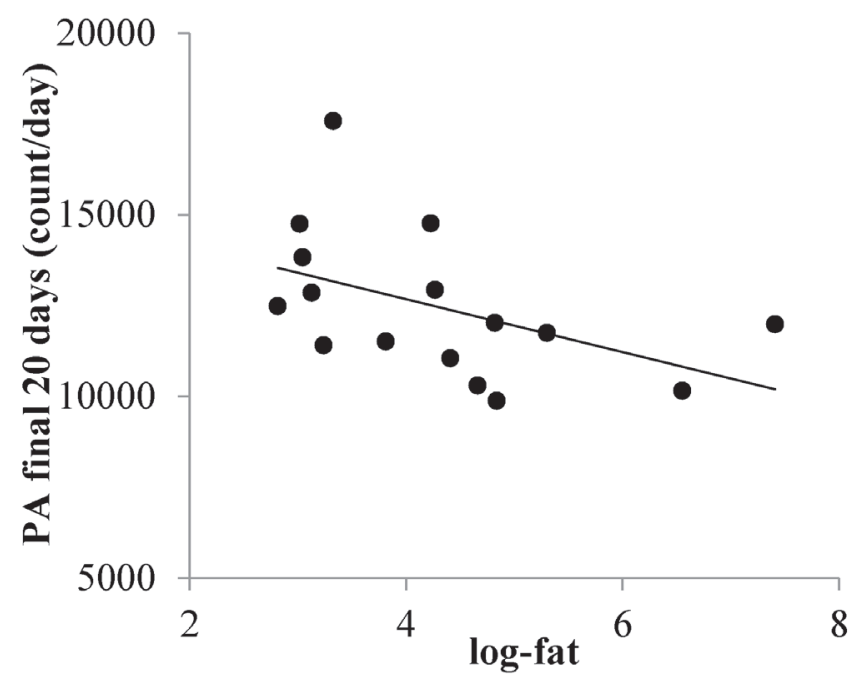

temperature data. A significant relationship was noted with FAA and insulin levels measured at end of PR (LSR: $r^{2}=$ $\left.0.329, \mathrm{~F}_{(1,13)}=7.21, p=0.021\right)$. Data for FAA counts $/ \mathrm{hr}$ at baseline and end of study are shown in Table 3 with relationship data shown in Table 4).

\section{Non-food anticipatory activity (Non-FAA)}

No change in non-FAA was apparent between the 12AL and PR groups over the duration of study (paired t-test: $\mathrm{t}_{15}=2.07, p=0.058$, Figure $8 \mathrm{~b}$ ). Non-FAA was not related to the FAA and no relationships between nonFAA and the sizes of the different tissues or circulating hormone levels were apparent (see Table 3 and Table 4).

\section{Comparison of responses to calorie and protein restriction (CR vs PR)}

With both the CR and PR experiments containing identically treated $12 \mathrm{AL}$ groups fed diets consisting $20 \%$ protein, comparisons were made to evaluate whether a reduction in calories or protein impacted on the activity of restricted animals. Comparing the two 12AL groups from the PR and CR studies, no differences were noted in total daily PA, FAA (Figure 13a) or non-FAA over the baseline period ( 2 sample $\mathrm{t}$-tests: $\mathrm{t}_{9}=0.5, p=0.632, \mathrm{t}_{9}=$ $-1.777, p=0.136$, and $\mathrm{t}_{9}=8.62, p=0.414$ respectively). Direct comparisons between the three PR groups and the protein level matched CR group also found no difference in PA, FAA or non-FAA over the baseline period, ie 20CR vs 20PR, 30CR vs 30PR and 40CR vs 40PR (2 sample

b)

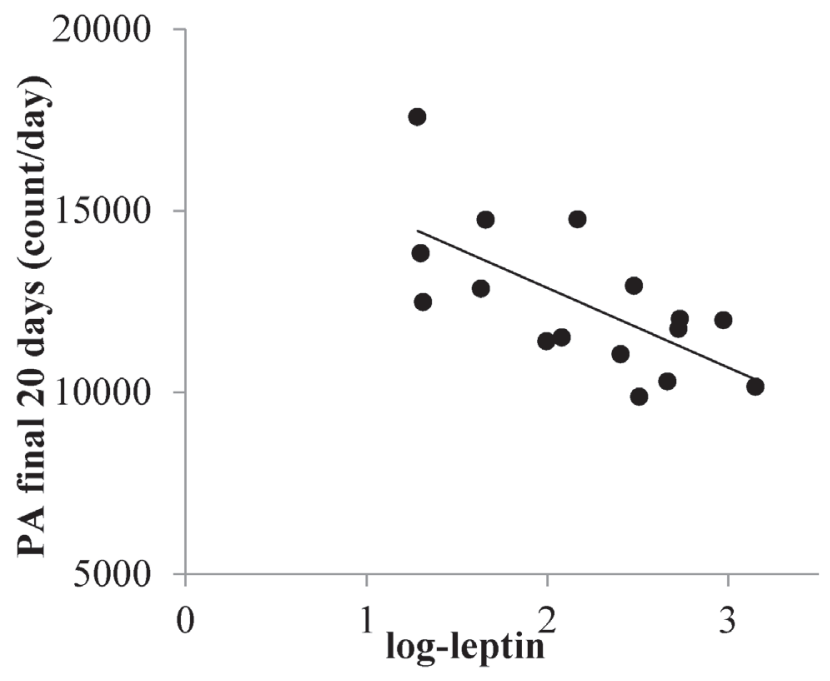

Figure 12: The relationship between total physical activity (PA), fat mass and circulating leptin levels in mice where protein levels were restricted by $20 \%, 30 \%$ or $40 \%$ (20PR, 30PR and 40PR). a. total daily PA vs fat and b. total daily PA and leptin. Fat mass data was taken from [11] and leptin data from [17]. 
t-tests: $\mathrm{p}>0.05)$.

Looking at the activity over the final 20 days of study, the 12AL group from both $\mathrm{CR}$ and PR studies behaved in a very similar manner for total daily PA and FAA (2 sample t-tests: $\mathrm{t}_{10}=-2.507, p=0.066, \mathrm{t}_{10}=-1.266$, $p=0.234$ ) but not non-FAA, which was lower in the $12 \mathrm{AL}$ group from the CR study $\left(\mathrm{t}_{10}=-3.218, p=0.009\right)$. Total daily PA at the end of the study was significantly higher in the animals fed 20PR $(13312, \mathrm{SD}=2563)$ than those fed 20CR (9906, SD = 1171) (2 sample t-test: $t_{11}=-3.308$, $\mathrm{p}=0.007)$. The total daily PA of the 30CR vs 30PR and 40CR vs 40PR were not significantly different (2 sample t-tests: $\mathrm{t}_{8}=-1.943, p=0.088$ and $\mathrm{t}_{9}=0.410, p=0.691$ respectively).

However analysis of FAA found the protein matched CR and PR treated animals responded very differently. Pronounced differences were found in FAA over the final 20 days between the groups matched for the levels of protein intake ie average FAA at end of study was twice as high in the 20CR compared to 20PR (2159, SD $=928$ vs $1093, \mathrm{SD}=254$ counts; 2 sample $\mathrm{t}$-test: $\mathrm{t}_{11}=$ $2.476, p=0.031$, Figure 13b). This was amplified as the restriction levels increased and FAA was 3 times greater in 30CR $(3144, \mathrm{SD}=1235)$ versus 30PR $(1017, \mathrm{SD}=276)$ (2 sample t-test: $\mathrm{t}_{8}=3.325, p=0.010$, Figure $13 \mathrm{c}$ ) and 5 times higher in 40CR $(4095, \mathrm{SD}=929)$ versus $40 \mathrm{PR}$ $(878, \mathrm{SD}=136)\left(2\right.$ sample t-test: $\mathrm{t}_{9}=5.783, p<0.0005$, Figure 13d).

As with the two 12AL groups, the level of nonFAA were significantly different in 20CR compared to 20PR and 30CR to 30PR groups. Non-FAA in 20CR mice was 1.5 times lower than the 20PR ( 2 sample $\mathrm{t}$-test: $\mathrm{t}_{11}=$ $-4.702, p<0.0005)$ and 1.6 times in the 30CR compared to 30PR ( 2 sample t-test: $\mathrm{t}_{8}=-4.976, p=0.001$ ). However at the end of the study the levels of non-FAA in the 40CR and 40PR were similar (7455, SD $=974$ and 9532, $\mathrm{SD}=$ 1382 respectively, 2 sample t-test: $\mathrm{t}_{9}=-1.267, p=0.237$ ).

Amassing these results, the associations between a)

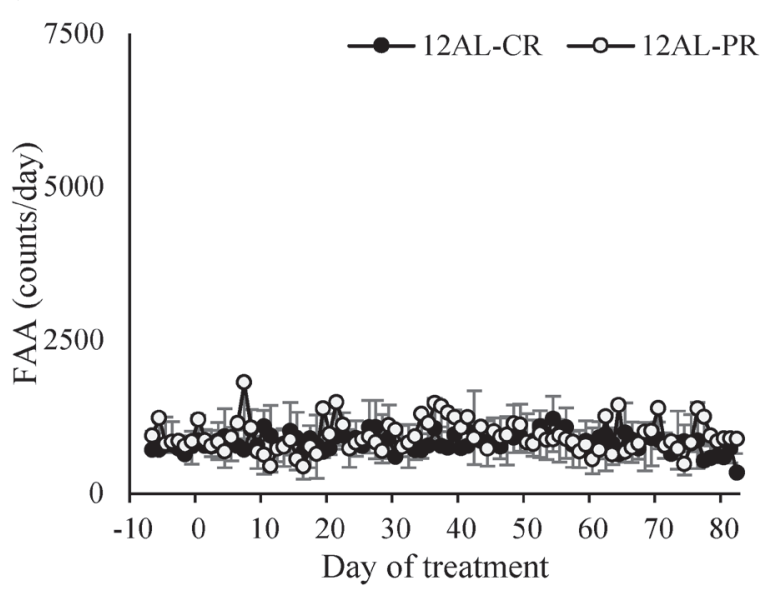

c)

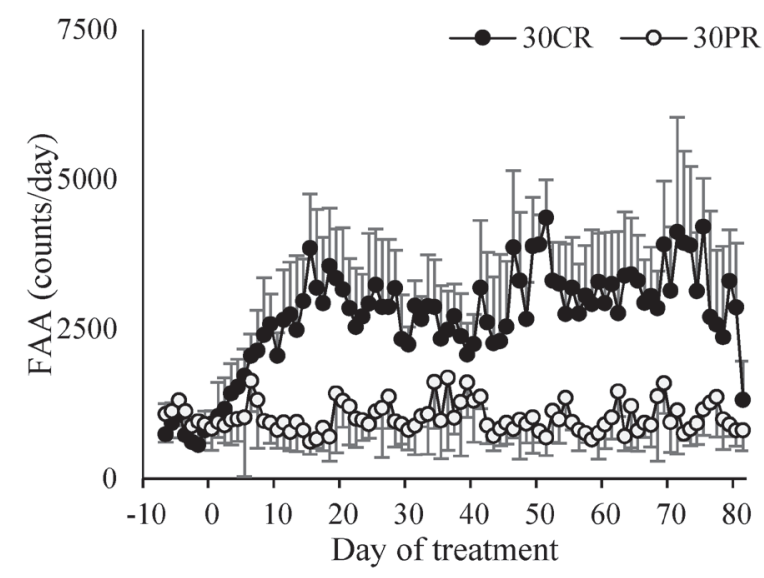

b)

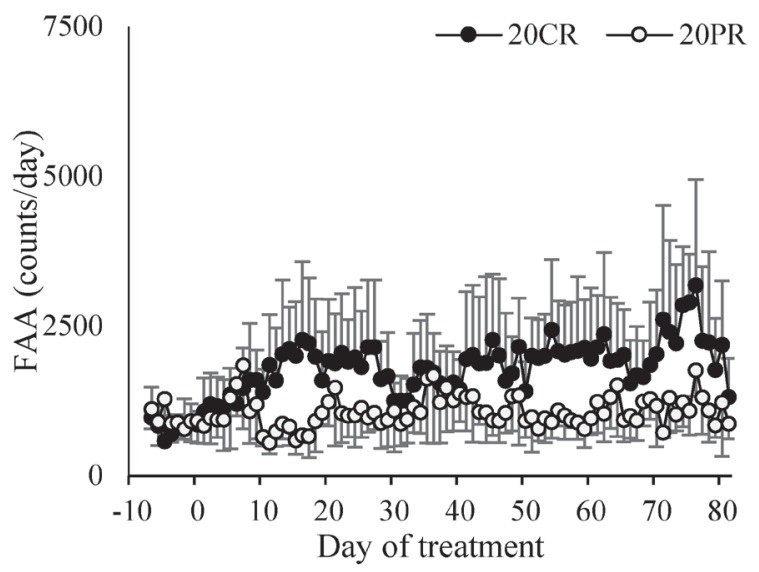

d)

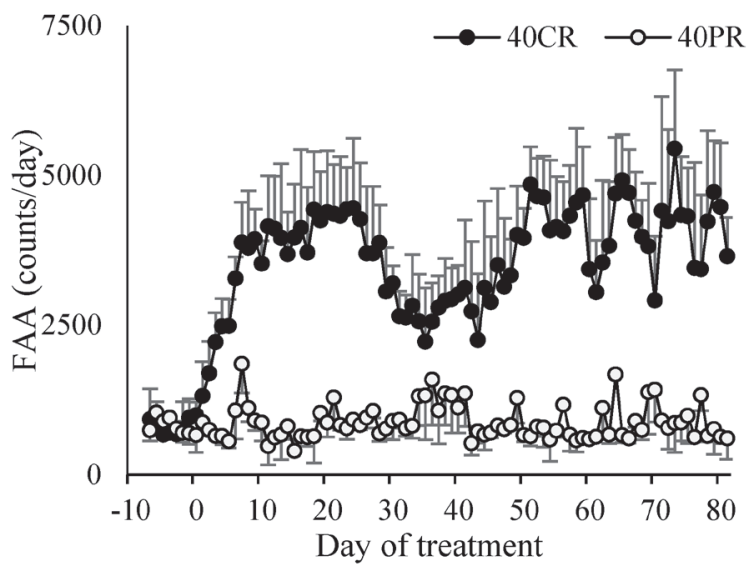

Figure 13: Comparisons of the food anticipatory activity (FAA) responses to caloric restriction (CR) and protein restriction (PR). FAA in a. control ad libitum fed mice (12AL) from both studies fed the same diet (20\% protein) available only during the hours of darkness. b., c. and d. show FAA response of the mice under 20, 30 and $40 \%$ CR matched to mice under 20,30 and $40 \%$ PR respectively. In each of these instances the level of protein was the same. All plots are presented on a common scale. The x-axis is the day of measurement. Day 0 is the start of restriction. Prior to that (negative days) all mice were at baseline and fed only during the 12 hours of darkness. ( $n=8$ individuals per group except in 30CR where $n=6$ ). Data is presented as mean \pm SD. 
the levels of CR, morphological and hormonal changes and their impact on PA are illustrated in Figure 14. Morphological changes in adipose tissues, structural tissues and vital organs impart changes in hormone levels which in turn, relay an effect on PA. In summary, leptin, insulin, TNF- $\alpha$ and IGF-1 levels are significantly negatively related to total PA and FAA. The levels of resistin and IL- 6 were not related to PA and none of the hormones measured influenced non-FAA. We emphasize that the associations in this figure reflect correlations and cannot be assumed to be causal.

\section{DISCUSSION}

\section{Calorie restriction}

Mice are normally nocturnal, resting in the light phase and more active over the dark phase. This circadian behavior is primarily determined by the daily lightdark cycle, and is controlled by the master clock in the suprachiasmatic nucleus (SCN) $[37,63]$. Other cues, such as food availability, are also capable of controlling sleep/ wake behaviors in mammals. As with many CR studies (reviewed in [3]), our mice were fed once a day. To minimize disturbance weighing and feeding was carried out immediately before lights out, to coincide with the natural circadian arousal pattern. Early speculations on the mechanisms behind the impact of CR on lifespan hypothesized the pro-longevity effect was mediated by concomitant increases in spontaneous activity. Several studies in rats have shown that the age-related decline in activity is retarded by CR [48, 67].

While we found a decrease in total daily PA over the 3 months of study, this was apparent in all groups, and no overall difference in the level of daily PA was detected between the AL and CR mice at the end of study. However contradictory reports exist in the literature and some found an increase $[34,68]$ while others a decrease $[35,36,69]$

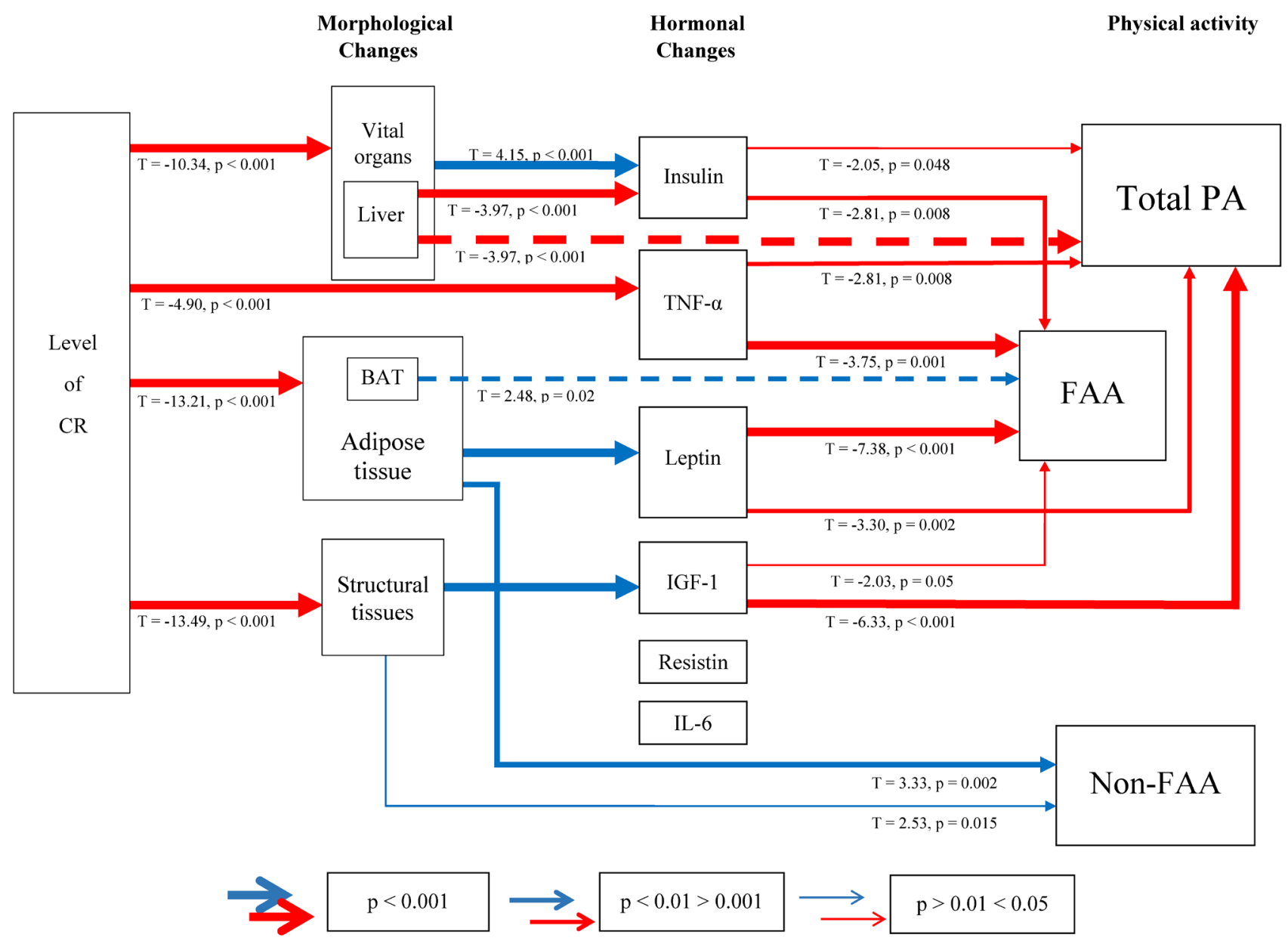

Figure 14: A schematic diagram depicting the interplay between morphological, hormonal changes and physical activity (PA) under calorie restriction (CR). PA was split into total daily PA, food anticipatory activity (FAA) and non-FAA. Relationships were generated using stepwise least squared multiple regression models. Positive relationships are shown in red and negative in blue. Increasing thickness in lines indicate increased significance. BAT $=$ brown adipose tissue, TNF- $\alpha=$ tumor necrosis factor- $\alpha$, IGF-1 = insulin-like growth factor-1, IL-6 = interleukin-6. 
in PA. Supporting our findings Cameron et al (2011) also found no difference in total levels of PA between the CR and AL mice, when CR was initiated at 14 months of age for 70 days [65]. Studies in non-human primates also found PA was not altered by CR [70], however studies on humans have reported decreased PA under CR [71, 72].

The change in the temporal patterning of PA throughout the day in response to $\mathrm{CR}$, as found here, has been reported previously by several groups $[32,65$, 73]. By fitting a Bayesian model Cameron et al (2011) found that, under $\mathrm{CR}$, mice compensated for bouts of high activity (FAA) by prolonged phases of inactivity [65]. However, results here revealed that while many of the mice responded to high FAA with a lower non-FAA, this was not the case for all mice ( 3 in particular having high FAA and non-FAA). What was also immediately apparent was the high variation in levels of PA in response to the higher levels of CR. While it would be intuitive to suppose increased PA would result a higher loss of weight, no relationship was apparent between total daily PA and body composition.

We previously reported that these mice compensated for the reduced energy supply under CR with a preferential utilization of body fat [11]. While no relationship between total daily PA and fat mass or structural tissues was apparent here, FAA was strongly correlated with both these morphological changes. The level of body fat was also related to non-FAA. The level of body fat is proportionally related to the secretion of leptin, a key regulator of energy balance, signaling a reduction in energy intake and an increase in energy expenditure [74]. While reduced levels of leptin, as a consequence of CR, might be predicted to be associated with a decrease in total PA, as a means of saving energy, hypoleptinemia, as found in the most restricted mice, was associated with increased total daily activity, particularly FAA. The role of leptin in PA control can be clearly defined in the leptin deficient $o b / o b$ mouse which is phenotypically obese and hypoactive [75]; characteristics which can be reversed by administration of leptin [76]. However, leptin control over PA may be more complicated with contrasting effects of leptin reported on locomotor activity and FAA [58]. Physiological levels of leptin resulted in an increase in locomotor activity which contrasted with a deficiency of leptin, which appeared to suppress FAA in $o b / o b$ mice [58]. In this study we found that, in addition to leptin, insulin, TNF- $\alpha$ and IGF-1 were strongly related to total PA and FAA and like leptin none of these other hormones influenced non-FAA.

While the roles of leptin and insulin as regulators of energy balance are well documented, less has been reported regarding the relationship between TNF- $\alpha$ and IGF-1 and energy balance. TNF- $\alpha$, a key inflammatory cytokine, also classed as an adipokine, is becoming known for its role in energy homeostasis [77, 78]. Elevated TNF- $\alpha$ was previously reported to have an important role in the depressed appetite symptomatic of infections and in conditions associated with disease such as cancer cachexia [79]. Recently a role of TNF- $\alpha$ in the lipopolysaccharide induced circadian effect on locomotor activity rhythm was suggested [80]. TNF- $\alpha$ levels in the mice studied here were reduced with CR [15]. While we show here that leptin, insulin, TNF- $\alpha$ and IGF-1 were associated with FAA a number of other hormones we did not measure have also been implicated in FAA control, eg. norepinephrine, dopamine and ghrelin. Regulation of FAA is clearly complex and not fully understood, and the complete ablation of FAA has not been observed in any gene knockout model studied to date.

FAA was first reported by Curt Paul Richter in rats in 1922 [81], since then it has been well documented in many mammals, fish and birds [39] with mice shown to anticipate as many as 4 of 6 daily meals [66]. Foraging for food in the wild is necessary for survival and FAA may reflect increased activity [41]. We found that after 3 months FAA comprised almost $40 \%$ of daily activity in mice under 40CR. A 4 fold increase in light phase activity in mice under a similar level of CR mice was previously reported [33]. The control of FAA appears to be distinct from the SCN; mice with lesions of the SCN and those lacking BMAL1, a critical gene for circadian rhythm, display a robust FAA response under restricted feeding $[82,83]$. Several food-entrainable oscillators have been discovered elsewhere in the brain and throughout the body, ie clock gene rhythms in stomach, intestine, pancreas, liver, adrenal, heart, lung, muscle and others all realign to the daily rhythm of food intake $[38,84]$. Here we found that mice subjected to higher levels of CR responded more acutely and exhibited greater intensity of FAA.

When faced with limited energy availability it would seem logical that energy saving mechanisms such as reduced basal metabolism and increases in the use of torpor would be activated. We found both total daily PA and FAA were correlated to $\mathrm{T}_{\mathrm{b}}$, in the mice that exhibited higher FAA had lower mean and minimum $T_{b}$ ie torpor $\left(T_{b}\right.$ $<31^{\circ} \mathrm{C}$ ). Note that over much shorter timescales (minutes rather than days), however, these associations were reversed and mice which had lower body temperature were less active [20]. At the scale of days rather than minutes, our data agreed with previous work showing that mice faced with high foraging costs (running) were more likely to employ torpor than mice exposed to low foraging costs [85]. Our results imply that energy saved by use of torpor could be cancelled out by the increased energy expended on FAA. Interestingly a positive association was found between BAT and FAA. BAT plays important role in the regulation of energy balance and CR has been shown to inhibit BAT thermogenesis and retard the age-related decline in mitochondrial function of BAT [86-88]. 


\section{Protein restriction}

Several studies have reported increases in longevity following PR (or specific amino acids such as tryptophan [89] or methionine [90]) and have implicated the specific reduction in protein to underlie the beneficial effect of CR. Our results found no indication of an effect of PR on total daily PA, FAA or non-FAA. While restricted feeding is a powerful zeitgeber and one of a limited number of external cues that can entrain the circadian clock and override the nocturnal activity rhythm [91], we found no evidence of changes in circadian rhythms in mice fed a restricted protein diet. Over a complex series of experiments, Mistlberger and colleagues sought to define macronutrient cues for FAA [92]. Their earlier work had shown mice developed nutrient-dependent FAA to sweetened meal [93], however, chronically protein deprived mice did not show anticipation for a single protein meal (this was also true for carbohydrate and fat). More recent research, however, has concluded glucose availability can produce FAA in rats [94]. Results here show FAA was due to restriction of calories alone with no evidence that equivalent levels of PR increased FAA.

Although in general the response to PR differed from the response to $\mathrm{CR}$, one area of similarity was in the relationship between fat mass, leptin and total PA levels. Under both CR and PR the relationships were both negative (Figures 3 and 12). This may reflect different processes in the different treatments. Under CR there was a major effect of the level of CR on body fatness [11] which led to very low leptin levels [17], and this was strongly related to the level of FAA (Figure 7c) thus driving the overall relationship between leptin and total PA (Figure 3a). In contrast the mice under PR did not show any FAA (Figure 13) hence the relationship between overall activity and leptin levels (Figure 12) could not be underpinned by an association between FAA and body fat/ leptin levels. We have previously shown that individual variation in PA levels in C57BL/6 mice can be a factor driving individual variability in weight and fat gain, with low activity hence predisposing to weight and fat gain and hence increased leptin levels [95]. Hence the relationship within the mice under PR may have come about because of this association.

In conclusion, no differences in average daily PA were found between $\mathrm{CR}$ treatment groups. Beneath this lack of difference however, there were tremendous differences in the temporal patterning of PA, in particular the balance between the levels of FAA and non-FAA. While most mice studied here appeared to show compensatory reduction in non-FAA when FAA was high, this was not always the case. Although there was a large variation in activity responses to $\mathrm{CR}$, the strong linear trend observed in FAA in relation to the level of restriction was consistent with the linear increase in lifespan [96]. This change in activity is unlikely to be mimicked in humans under CR treatment. Hence, if it plays a role in the life extending impact of CR such benefits will be unlikely to translate to humans. Separately, CR and exercise have been shown to increase mean lifespan in rodents, but CR and not exercise can impact on maximum longevity [46, 97]. While both strategies induce a leaner body mass (less fat mass) with similar health benefits observed, there is no additive effect and the combination of CR and exercise did not extend lifespan further than CR alone [48, $97,98]$. While many similarities exist, there are clearly fundamental differences between these two interventions. Voluntary exercise improved heart health via reductions in production of hydrogen peroxide [99]. Yet, despite decreased levels of IGF-1 and reduced DNA damage in exercised ad libitum fed rats compared to sedentary controls and exercising animals which had increased insulin sensitivity relative to their CR counterparts, exercise is unable to mimic the life extending effect of CR [100-101].

\section{EXPERIMENTAL PROCEDURES}

\section{Animals}

The rationale and design of the study has been detailed previously [11]. All procedures were reviewed and approved by University of Aberdeen ethical approval committee and carried out under a Home Office issued license compliant with the Animals (Scientific Procedures) Act 1986. In brief male C57/BL6 mice (Charles River, Ormiston, UK) were acclimated for 6 weeks prior to implantation of transmitters at 12 weeks of age, allowing adequate recovery time prior to experimentation. A number of baseline measurements, including dual X-ray absorptiometry (DXA) for body composition, glucose tolerance tests (GTT) and resting metabolic rate, were carried out at 17-18 weeks old. Over the baseline period all animals were provided with ad libitum access to water. Open source diet (D12450B, Research Diets, NJ, USA) containing $20 \%$ protein, $70 \%$ carbohydrate and $10 \%$ fat (by energy) was provided in the 12 hours of darkness only.

CR or PR was begun at 20 weeks of age, approximately equivalent to early adulthood of humans. In the CR study all mice continued to be fed D12450B with restriction levels set at 10\%, 20\%,30\% and $40 \%$ (referred to as $10 \mathrm{CR}, 20 \mathrm{CR}, 30 \mathrm{CR}$ and $40 \mathrm{CR}$ ) of individual baseline food intake For the PR study diets were designed to match the reduced protein level of the 20CR, 30CR and $40 \mathrm{CR}$, ie protein content was equivalent to 16,14 and $12 \%$ protein (made up by increased carbohydrate) (D13020201, D13020202 and D13020203 respectively, Research Diets, NJ, USA). These are referred to as 20PR, 30PR and 40PR. Mice may compensate for the reduced protein intake by overeating; this was prevented by feeding a fixed weight 
of food equivalent to their own individual baseline intake on D12450B (20\% protein). All four diets were isocaloric $(3.8 \mathrm{kcal} / \mathrm{g})$ and the duration of restriction phase was 3 months.

With mice naturally nocturnal, $24 \mathrm{hr}$ access to food may also invoke unnatural overeating leading to obesity. This can be problematic when used as controls against restricted feeding $[3,102]$. Therefore an additional group where access to food was limited to the 12 hours of darkness was used as a control and referred to as $12 \mathrm{AL}$. Food intake of the 12AL and 24AL groups did not differ significantly [11]. To minimize light phase disturbances mice were fed once per day, immediately prior to lights out and food was removed at the onset of light phase. Both CR and PR studies utilized a control 12AL group with animals treated identically. Mice were killed on day 90 of restriction between 1400 and $1700 \mathrm{~h}$ to minimize any circadian effects on hormone levels and body composition [11].

\section{VitalView $^{\mathrm{TM}}$}

Physical activity (PA) (and core body temperature) were measured using the VitalView ${ }^{\mathrm{TM}}$ telemetry and data acquisition system (MiniMitter, OR, USA). The transmitters, implanted intraperitoneally, are unrestrictive allowing free movement of the animals. Minute by minute recordings are transmitted via an ER-4000 receiving platform and VitalView ${ }^{\mathrm{TM}}$ software was used to acquire data (MiniMitter, OR, USA). For a full description of the system refer to [103]. Due to a malfunction of 2 transmitters post implantation $n=8$ for all groups bar 30CR where $n=6$. Animals were undisturbed except for feeding, weighing and routine checks.

\section{Statistical analysis}

Statistical analyses were performed using the IBM SPSS Statistics package 23 and Minitab version 17. Data was checked for normal distribution using the Kolmogorov-Smirnov test and log transformed where applicable. The current analysis concerns data summarized over time periods of days, and major subcomponents of whole days. For an analysis of activity of the same mice at the time scale of minutes refer to [19]. The minute by minute data summed over $24 \mathrm{~h}$ was called total daily activity. The sum over the $2 \mathrm{hr}$ prior to feeding was called food anticipatory activity (FAA) and this was subtracted from the total activity to give non-FAA. These three types of activity were analyzed separately. The effect of the level of CR over the course of the study was explored using general linear model (GLM) with repeated measurements (RM). Where significance was achieved between treatment groups post hoc Tukey tests were used. One way ANOVA was used for comparison between groups at the end of the study. Paired or 2 sample t-tests were used where appropriate. Quadratic equations were fitted to the data and the time to reach the nadir in activity and the initial rate of change from the onset of restriction were derived from these fitted equations. The relationships between total daily PA, FAA and non-FAA over the last 20 days of the experiment with body composition, circulating hormone levels and corresponding body temperatures measured at the end of the experiment we determined using least squares single and multiple regression analysis (LSR), eliminating non-significant terms using a backward elimination stepwise procedure. Linear regression analyses were verified by exploration of the diagnostic plots of residuals against fitted values. For detailed protocols of body composition, hormone and body temperature measurements please refer to $[11,15,17]$ respectively. All data are shown as mean \pm standard deviation (SD) with results considered statistically significant at $\mathrm{p} \leq 0.05$.

\section{CONFLICTS OF INTEREST}

The authors declare no conflicts of interest.

\section{REFERENCS}

1. Turturro A, Duffy P, Hass B, Kodell R, Hart R. Survival characteristics and age-adjusted disease incidences in C57BL/6 mice fed a commonly used cereal-based diet modulated by dietary restriction. The Journals of Gerontology Series A: Biological Sciences and Medical Sciences. 2002; 57:B379-B389.

2. Fontana L, Partridge L, Longo VD. Extending healthy life span—from yeast to humans. Science. 2010; 328:321-326.

3. Speakman JR, Mitchell SE. Caloric restriction. Mol Aspects Med. 2011; 32:159-221.

4. Mattison JA, Roth GS, Beasley TM, Tilmont EM, Handy AM, Herbert RL, Longo DL, Allison DB, Young JE, Bryant M, Barnard D, Ward WF, Qi W et al. Impact of caloric restriction on health and survival in rhesus monkeys from the NIA study. Nature. 2012; 489:318-321.

5. Mair W, Piper MD, Partridge L. Calories do not explain extension of life span by dietary restriction in Drosophila. PLoS Biol. 2005 3:e223.

6. Youngman LD. Protein restriction (PR) and caloric restriction (CR) compared: Effects on DNA damage, carcinogenesis, and oxidative damage. Mutation Research/ DNAging. 1993; 295:165-179.

7. Solon-Biet SM, McMahon AC, Ballard JWO, Ruohonen K, Wu LE, Cogger VC, Warren A, Huang X, Pichaud N, Melvin RG. The ratio of macronutrients, not caloric intake, dictates cardiometabolic health, aging, and longevity in ad libitum-fed mice. Cell Metabolism. 2014; 19:418-430.

8. Rizza W, Veronese N, Fontana L. What are the roles of calorie restriction and diet quality in promoting healthy longevity? Ageing Research Reviews. 2014; 13:38-45. 
9. Bertrand HA, Lynd FT, Masoro EJ, Yu BP. Changes in adipose mass and cellularity through the adult life of rats fed ad libitum or a life-prolonging restricted diet. J Gerontol. 1980; 35:827-835.

10. Barzilai N, Gupta G. Revisiting the role of fat mass in the life extension induced by caloric restriction. J Gerontol A Biol Sci Med Sci. 1999; 54:B89-96.

11. Mitchell SE, Tang ZH, Kerbois C, Delville C, Konstantopedos P, Bruel A, Derous D, Green C, Aspden RM, Goodyear SR, Chen L, Han JJD, Wang Y et al. The effects of graded levels of calorie restriction: I. impact of short term calorie and protein restriction on body composition in the C57BL/6 mouse. Oncotarget. 2015; 6:15902-15930. doi: 10.18632/oncotarget.4142.

12. Tatar M, Bartke A, Antebi A. The endocrine regulation of aging by insulin-like signals. Science. 2003; 299:13461351.

13. Rincon M, Rudin E, Barzilai N. The insulin/IGF-1 signaling in mammals and its relevance to human longevity. Exp Gerontol. 2005; 40:873-877.

14. Junnila RK, List EO, Berryman DE, Murrey JW, Kopchick JJ. The GH/IGF-1 axis in ageing and longevity. Nature Reviews Endocrinology. 2013; 9:366-376.

15. Mitchell SE, Delville C, Konstantopedos P, Hurst J, Derous D, Green C, Chen L, Han JJ, Wang Y, Promislow DE. The effects of graded levels of calorie restriction: II. impact of short term calorie and protein restriction on circulating hormone levels, glucose homeostasis and oxidative stress in male C57BL/6 mice. Oncotarget. 2015; 6:23213-23237. doi: 10.18632/oncotarget.4003.

16. Lane MA, Baer DJ, Rumpler WV, Weindruch R, Ingram DK, Tilmont EM, Cutler RG, Roth GS. Calorie restriction lowers body temperature in rhesus monkeys, consistent with a postulated anti-aging mechanism in rodents. Proceedings of the National Academy of Sciences. 1996; 93:4159-4164.

17. Mitchell SE, Delville C, Konstantopedos P, Derous D, Green CL, Chen L, Han JD, Wang Y, Promislow DE, Douglas A, Lusseau D, Speakman JR. The effects of graded levels of calorie restriction: III. impact of short term calorie and protein restriction on mean daily body temperature and torpor use in the C57BL/6 mouse. Oncotarget. 2015; 6:18314-18337. doi: 10.18632/oncotarget.4506.

18. McNamara JM, Houston AI. State-dependent life histories. Nature. 1996; 380:215-221.

19. Lusseau D, Mitchell SE, Barros C, Derous D, Green C, Chen L, Han JJ, Wang Y, Promislow DE, Douglas A. The effects of graded levels of calorie restriction: IV. non-linear change in behavioural phenotype of mice in response to short-term calorie restriction. Scientific Reports. 2015; 5.

20. Bartke A, Wright JC, Mattison JA, Ingram DK, Miller RA, Roth GS. Longevity: Extending the lifespan of long-lived mice. Nature. 2001; 414:412-412.

21. Ikeno Y, Lew CM, Cortez LA, Webb CR, Lee S, Hubbard GB. Do long-lived mutant and calorie-restricted mice share common anti-aging mechanisms? - a pathological point of view. Age. 2006; 28:163-171.

22. Brown-Borg H, Johnson WT, Rakoczy S. Expression of oxidative phosphorylation components in mitochondria of long-living Ames dwarf mice. Age. 2012; 34:43-57.

23. Conti B, Sanchez-Alavez M, Winsky-Sommerer R, Morale MC, Lucero J, Brownell S, Fabre V, Huitron-Resendiz S, Henriksen S, Zorrilla EP, de Lecea L, Bartfai T. Transgenic mice with a reduced core body temperature have an increased life span. Science. 2006; 314:825-828.24.

24. Koizumi A, Wada Y, Tuskada M, Kayo T, Naruse M, Horiuchi K, Mogi T, Yoshioka M, Sasaki M, Miyamaura Y. A tumor preventive effect of dietary restriction is antagonized by a high housing temperature through deprivation of torpor. Mech Ageing Dev. 1996; 92:67-82.

25. Roth GS, Lane MA, Ingram DK, Mattison JA, Elahi D, Tobin JD, Muller D, Metter EJ. Biomarkers of caloric restriction may predict longevity in humans. Science. 2002; 297:811-811.

26. Kenyon C. The first long-lived mutants: Discovery of the insulin/IGF-1 pathway for ageing. Philosophical Transactions of the Royal Society B: Biological Sciences. 2011; 366:9-16.

27. Gems D, Partridge L. Insulin/IGF signalling and ageing: Seeing the bigger picture. Curr Opin Genet Dev. 2001; 11:287-292.

28. Hall KD, Heymsfield SB, Kemnitz JW, Klein S, Schoeller DA, Speakman JR. Energy balance and its components: Implications for body weight regulation. Am J Clin Nutr. 2012; 95:989-994.

29. Copes LE, Schutz H, Dlugosz EM, Acosta W, Chappell MA, Garland T. Effects of voluntary exercise on spontaneous physical activity and food consumption in mice: Results from an artificial selection experiment. Physiol Behav. 2015; 149:86-94.

30. Garland T,Jr, Schutz H, Chappell MA, Keeney BK, Meek TH, Copes LE, Acosta W, Drenowatz C, Maciel RC, van Dijk G, Kotz CM, Eisenmann JC. The biological control of voluntary exercise, spontaneous physical activity and daily energy expenditure in relation to obesity: Human and rodent perspectives. J Exp Biol. 2011; 214:206-229.

31. Duffy PH, Feuers RJ, Leakey JA, Nakamura KD, Turturro A, Hart RW. Effect of chronic caloric restriction on physiological variables related to energy metabolism in the male Fischer 344 rat. Mech Ageing Dev. 1989; 48:117-133.

32. Duffy PH, Leakey JEA, Pipkin JL, Turturro A, Hart RW. The physiologic, neurologic, and behavioral effects of caloric restriction related to aging, disease, and environmental factors. Environ Res. 1997; 73:242-248.

33. Overton JM, Williams TD. Behavioral and physiologic responses to caloric restriction in mice. Physiol Behav. 2004; 81:749-754.

34. Carter CS, Leeuwenburgh C, Daniels M, Foster TC. Influence of calorie restriction on measures of age-related 
cognitive decline: Role of increased physical activity. The Journals of Gerontology Series A: Biological Sciences and Medical Sciences. 2009; 64A:850-859.

35. Hambly C, Speakman JR. Contribution of different mechanisms to compensation for energy restriction in the mouse. Obes Res. 2005; 13:1548-1557.

36. Golightly A, Boys RJ, Cameron KM, Zglinicki Tv. The effect of late onset, short-term caloric restriction on the core temperature and physical activity in mice. Journal of the Royal Statistical Society: Series C (Applied Statistics). 2012; 61:733-751.

37. Challet E, Mendoza J, Dardente H, Pévet P. Neurogenetics of food anticipation. Eur J Neurosci. 2009; 30:1676-1687.

38. Mistlberger RE. Neurobiology of food anticipatory circadian rhythms. Physiol Behav. 2011; 104:535-545.

39. Mistlberger RE. Circadian food-anticipatory activity: Formal models and physiological mechanisms. Neuroscience \& Biobehavioral Reviews. 1994; 18:171-195.

40. Abrams PA. Life history and the relationship between food availability and foraging effort. Ecology. 1991:1242-1252.

41. McCue MD. Starvation physiology: Reviewing the different strategies animals use to survive a common challenge. Comparative Biochemistry and Physiology Part A: Molecular \& Integrative Physiology. 2010; 156:1-18.

42. Weiss EP, Racette SB, Villareal DT, Fontana L, Steger-May K, Schechtman KB, Klein S, Holloszy JO. Improvements in glucose tolerance and insulin action induced by increasing energy expenditure or decreasing energy intake: A randomized controlled trial. Am J Clin Nutr. 2006; 84:1033-1042.

43. Fontana L, Meyer TE, Klein S, Holloszy JO. Long-term low-calorie low-protein vegan diet and endurance exercise are associated with low cardiometabolic risk. Rejuvenation Research. 2007; 10:225-234.

44. Fontana L, Klein S, Holloszy JO. Effects of long-term calorie restriction and endurance exercise on glucose tolerance, insulin action, and adipokine production. Age (Dordr). 2010; 32:97-108.

45. Mercken EM, Carboneau BA, Krzysik-Walker SM, de Cabo R. Of mice and men: The benefits of caloric restriction, exercise, and mimetics. Ageing Research Reviews. 2012; 11:390-398.

46. Holloszy JO, Smith EK, Vining M, Adams S. Effect of voluntary exercise on longevity of rats. J Appl Physiol (1985). 1985; 59:826-831.

47. Navarro A, Gomez C, Lopez-Cepero JM, Boveris A. Beneficial effects of moderate exercise on mice aging: Survival, behavior, oxidative stress, and mitochondrial electron transfer. Am J Physiol Regul Integr Comp Physiol. 2004; 286:R505-11.

48. McCarter R, Shimokawa I, Ikeno Y, Higami Y, Hubbard G, Yu B, McMahan C. Physical activity as a factor in the action of dietary restriction on aging: Effects in Fischer 344 rats. Aging Clinical and Experimental Research. 1997;
9:73-79.

49. Mattison J, Wright C, Bronson R, Roth G, Ingram D, Bartke A. Studies of aging in Ames dwarf mice: Effects of caloric restriction. Journal of the American Aging Association. 2000; 23:9-16.

50. Thorburn A, Proietto J. Biological determinants of spontaneous physical activity. Obesity Reviews. 2000; 1:87-94.

51. Schwartz MW, Figlewicz DP, Baskin DG, Woods SC, Porte Jr D. Insulin in the brain: A hormonal regulator of energy balance*. Endocr Rev. 1992; 13:387-414.

52. Baskin DG, Figlewicz Lattemann D, Seeley RJ, Woods SC, Porte D, Schwartz MW. Insulin and leptin: Dual adiposity signals to the brain for the regulation of food intake and body weight. Brain Res. 1999; 848:114-123.

53. Woods SC, Seeley RJ. Adiposity signals and the control of energy homeostasis. Nutrition. 2000; 16:894-902.

54. Morton GJ, Cummings DE, Baskin DG, Barsh GS, Schwartz MW. Central nervous system control of food intake and body weight. Nature. 2006; 443:289-295.

55. Ceccarini G, Maffei M, Vitti P, Santini F. Fuel homeostasis and locomotor behavior: Role of leptin and melanocortin pathways. J Endocrinol Invest. 2014:1-7.

56. Coppari R, Ichinose M, Lee CE, Pullen AE, Kenny CD, McGovern RA, Tang V, Liu SM, Ludwig T, Chua SC. The hypothalamic arcuate nucleus: A key site for mediating leptin's effects on glucose homeostasis and locomotor activity. Cell Metabolism. 2005; 1:63-72.

57. Huo L, Gamber K, Greeley S, Silva J, Huntoon N, Leng $\mathrm{X}$, Bjørbæk C. Leptin-dependent control of glucose balance and locomotor activity by POMC neurons. Cell Metabolism. 2009; 9:537-547.

58. Ribeiro AC, Ceccarini G, DuprÃ $\subset$ C, Friedman JM, Pfaff DW, Mark AL. Contrasting effects of leptin on food anticipatory and total locomotor activity. PLoS ONE. 2011; 6:e23364.

59. Mercer JG, Hoggard N, Williams LM, Lawrence CB, Hannah LT, Trayhurn P. Localization of leptin receptor mRNA and the long form splice variant (ob-rb) in mouse hypothalamus and adjacent brain regions by in situ hybridization. FEBS Lett. 1996; 387:113-116.

60. Schwartz MW. Brain pathways controlling food intake and body weight. Exp Biol Med. 2001; 226:978-981.

61. Blouet C, Schwartz GJ. Hypothalamic nutrient sensing in the control of energy homeostasis. Behav Brain Res. 2010; 209:1-12.

62. Nelson W, Halberg F. Meal-timing, circadian rhythms and life span of mice. J Nutr. 1986; 116:2244-2253.

63. Froy O. Circadian rhythms, aging, and life span in mammals. Physiology. 2011; 26:225-235.

64. Gutman R, Genzer Y, Chapnik N, Miskin R, Froy O. Longlived mice exhibit $24 \mathrm{~h}$ locomotor circadian rhythms at young and old age. Exp Gerontol. 2011; 46:606-609. 
65. Cameron KM, Golightly A, Miwa S, Speakman J, Boys R, von Zglinicki T. Gross energy metabolism in mice under late onset, short term caloric restriction. Mech Ageing Dev. 2011; 132:202-209.

66. Luby MD, Hsu CT, Shuster SA, Gallardo CM, Mistlberger RE, King OD, Steele AD. Food anticipatory activity behavior of mice across a wide range of circadian and noncircadian intervals. PLoS ONE. 2012; 7.

67. Yu BP, Masoro EJ, McMahan CA. Nutritional influences on aging of Fischer 344 rats: I. physical, metabolic, and longevity characteristics. Journal of Gerontology. 1985; 40:657-670.

68. Harrison DE, Archer JR. Genetic differences in effects of food restriction on aging in mice. J Nutr. 1987; 117:376382.

69. Rikke BA, Yerg JE, Battaglia ME, Nagy TR, Allison DB, Johnson TE. Strain variation in the response of body temperature to dietary restriction. Mech Ageing Dev. 2003; 124:663-678.

70. Heilbronn LK, Ravussin E. Calorie restriction and aging: Review of the literature and implications for studies in humans. Am J Clin Nutr. 2003; 78:361-369.

71. Martin CK, Heilbronn LK, de Jonge L, DeLany JP, Volaufova J, Anton SD, Redman LM, Smith SR, Ravussin E. Effect of calorie restriction on resting metabolic rate and spontaneous physical activity. Obesity. 2007; 15:29642973.

72. Redman LM, Martin CK, Williamson DA, Ravussin E. Effect of caloric restriction in non-obese humans on physiological, psychological and behavioral outcomes. Physiol Behav. 2008; 94:643-648.

73. Weed JL, Lane MA, Roth GS, Speer DL, Ingram DK. Activity measures in rhesus monkeys on long-term calorie restriction. Physiol Behav. 1997; 62:97-103.

74. Zhang Y, Proenca R, Maffei M, Barone M, Leopold L, Friedman JM. Positional cloning of the mouse obese gene and its human homologue. Nature. 1994; 372:425-432.

75. Mayer J. Decreased activity and energy balance in the hereditary obesity-diabetes syndrome of mice. Science. 1953; 117:504-505.

76. Pelleymounter MA, Cullen MJ, Baker MB, Hecht R, Winters D, Boone T, Collins F. Effects of the obese gene product on body weight regulation in ob/ob mice. Science. 1995; 269:540-543.

77. Pamir N, McMillen TS, Kaiyala KJ, Schwartz MW, LeBoeuf RC. Receptors for tumor necrosis factor-a play a protective role against obesity and alter adipose tissue macrophage status. Endocrinology. 2009; 150:4124-4134.

78. Hambly C, Duncan JS, Archer ZA, Moar KM, Mercer JG, Speakman JR. Repletion of TNFa or leptin in calorically restricted mice suppresses post-restriction hyperphagia. Disease Models \& Mechanisms. 2012; 5:83-94.

79. Argilés JM, Busquets S, García-Martínez C, López-Soriano FJ. Mediators involved in the cancer anorexia-cachexia syndrome: Past, present, and future. Nutrition. 2005; 21:977-985.

80. Paladino N, Mul Fedele ML, Duhart JM, Marpegan L, Golombek DA. Modulation of mammalian circadian rhythms by tumor necrosis factor-a. Chronobiol Int. 2014; 31:668-679.

81. Richter CP. A behavioristic study of the activity of the rat. Comparative Psychology Monographs. 1922; 1:1.

82. Stephan FK, Swann JM, Sisk CL. Anticipation of 24-hr feeding schedules in rats with lesions of the suprachiasmatic nucleus. Behav Neural Biol. 1979; 25:346-363.

83. Pendergast JS, Nakamura W, Friday RC, Hatanaka F, Takumi T, Yamazaki S. Robust food anticipatory activity in BMAL1-deficient mice. PLoS ONE. 2009; 4:e4860.

84. Escobar C, Cailotto C, Angeles-Castellanos M, Delgado RS, Buijs RM. Peripheral oscillators: The driving force for food-anticipatory activity. Eur J Neurosci. 2009; 30:16651675.

85. Schubert KA, Boerema AS, Vaanholt LM, de Boer SF, Strijkstra AM, Daan S. Daily torpor in mice: High foraging costs trigger energy-saving hypothermia. Biol Lett. 2010; 6:132-135.

86. Rothwell NJ, Stock MJ, Tyzbir RS. Energy balance and mitochondrial function in liver and brown fat of rats fed "cafeteria" diets of varying protein content. J Nutr. 1982; 112:1663-1672.

87. Cannon B, Nedergaard J. Brown adipose tissue: Function and physiological significance. Physiol Rev. 2004; 84:277359.

88. Valle A, Guevara R, García-Palmer FJ, Roca P, Oliver J. Caloric restriction retards the age-related decline in mitochondrial function of brown adipose tissue. Rejuvenation Research. 2008; 11:597-604.

89. de Marte ML, Enesco HE. Influence of low tryptophan diet on survival and organ growth in mice. Mech Ageing Dev. 1986; 36:161-171.

90. Miller RA, Buehner G, Chang Y, Harper JM, Sigler R, Smith-Wheelock M. Methionine-deficient diet extends mouse lifespan, slows immune and lens aging, alters glucose, T4, IGF-I and insulin levels, and increases hepatocyte MIF levels and stress resistance. Aging Cell. 2005; 4:119-125.

91. Hsu CT, Patton DF, Mistlberger RE, Steele AD. Palatable meal anticipation in mice. PLoS One. 2010; 5:e12903.

92. Mistlberger RE, Houpt TA, Moore-Ede MC. Foodanticipatory rhythms under 24-hour schedules of limited access to single macronutrients. J Biol Rhythms. 1990; 5:35-46.

93. Mistlberger R, Rusak B. Palatable daily meals entrain anticipatory activity rhythms in free-feeding rats: Dependence on meal size and nutrient content. Physiol Behav. 1987; 41:219-226.

94. Carneiro BT, Fernandes DA, Medeiros CF, Diniz NL, Araujo JF. Daily anticipatory rhythms of behavior and 
body temperature in response to glucose availability in rats. Psychology \& Neuroscience. 2012; 5:191.

95. Zhang, L.N., Morgan, D., Clapham, J.C. and Speakman, J.R. Factors predicting non-genetic variability in body weight gain induced by a high fat diet in inbred C57BL/6J mice. Obesity 2012; 20: 1179-88

96. Speakman JR, Hambly C. Starving for life: What animal studies can and cannot tell us about the use of caloric restriction to prolong human lifespan. J Nutr. 2007; 137:1078-1086.

97. Holloszy JO, Schechtman KB. Interaction between exercise and food restriction: Effects on longevity of male rats. J Appl Physiol (1985). 1991; 70:1529-1535.

98. Huffman DM, Moellering DR, Grizzle WE, Stockard CR, Johnson MS, Nagy TR. Effect of exercise and calorie restriction on biomarkers of aging in mice. Am J Physiol Regul Integr Comp Physiol. 2008; 294:R1618-27.
99. Judge S, Jang YM, Smith A, Selman C, Phillips T, Speakman, J.R., Hagen T, Leeuwenburg, C. Exercise by lifelong voluntary wheel running reduces subsarcolemmal and interfibrillar mitochondrial hydrogen peroxide production in the heart. American Journal of Physiology; 2005 289: R1564-1572

100. Oscai LB, Holloszy JO. Effects of weight changes produced by exercise, food restriction, or overeating on body composition. J Clin Invest. 1969; 48:2124-2128.

101. Holloszy JO. Mortality rate and longevity of food-restricted exercising male rats: A reevaluation. J Appl Physiol (1985). 1997; 82:399-403.

102. Sohal RS, Forster MJ. Caloric restriction and the aging process: A critique. Free Radical Biology and Medicine. 2014; 73:366-382.

103. Harkin A, O'Donnell JM, Kelly JP. A study of VitalView ${ }^{\mathrm{TM}}$ for behavioural and physiological monitoring in laboratory rats. Physiol Behav. 2002; 77:65-77. 